\title{
Investigation of heat management for CLC of syngas in packed bed reactors
}

\author{
V. Spallina ${ }^{\text {a }}$, F. Gallucci ${ }^{\text {b }}$, M.C. Romano ${ }^{\text {a }}$, P. Chiesa ${ }^{a}$, G. Lozza ${ }^{a}$, M. van Sint Annaland ${ }^{b, *}$ \\ ${ }^{a}$ Group of Energy Conversion Systems, Energy Department, Politecnico of Milano, Milano, Italy \\ ${ }^{\mathrm{b}}$ Multiphase Reactors, Chemical Process Intensification, Chemical Engineering and Chemistry, Eindhoven University of Technology, Eindhoven, The Netherlands
}

\section{H I G H L I G H T S}

- The feasibility of packed bed CLC with syngas as the fuel is assessed.

- New operation strategies are discussed to use ilmenite as oxygen carrier.

- High efficiency process can be obtained also with less active oxygen carriers.

\section{G R A P H I C A L A B S T R A C T}

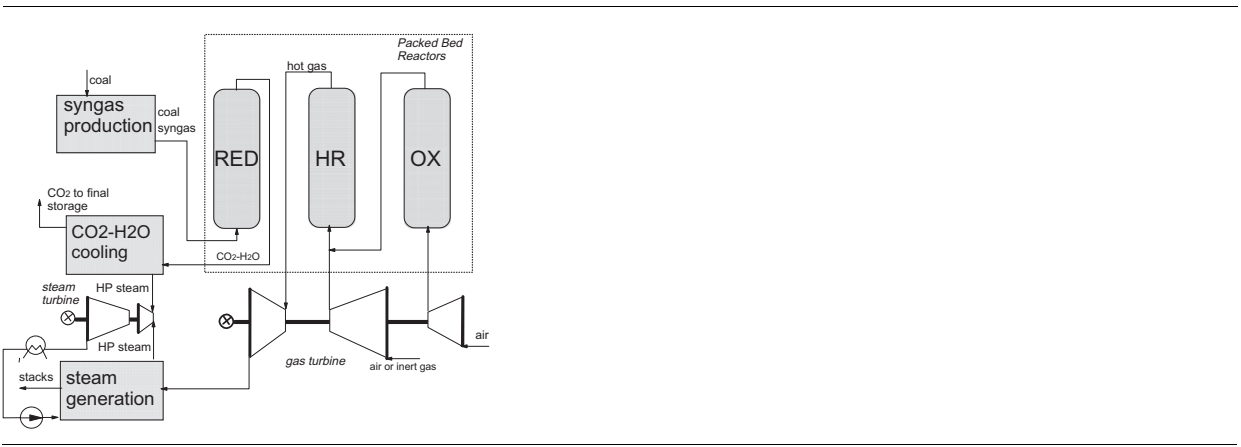

\section{A R T I C L E I N F O}

\section{Article history:}

Received 1 February 2013

Received in revised form 8 March 2013

Accepted 12 March 2013

Available online 21 March 2013

\section{Keywords:}

Packed bed reactors

Chemical looping combustion

Heat management

Oxygen carrier conversion

Coal plants

$\mathrm{CO}_{2}$ capture

\begin{abstract}
A B S T R A C T
Different configurations for an adequate heat management in dynamically operated packed bed reactors for Chemical Looping Combustion (CLC) have been investigated and compared using syngas from a coal gasification unit as fuel. Ilmenite has been selected as oxygen carrier for the process mainly because its high melting point, allowing to reach high temperature close to $1200^{\circ} \mathrm{C}$, excellent selectivity to the formation of $\mathrm{CO}_{2}$, natural availability and related low cost. Packed bed reactors for chemical looping combustion processes have recently been proposed as alternative to the interconnected fluidized bed reactors for pressurized systems, because solid circulation and gas-solid separation are not required. Due to the transient behavior of packed bed reactors, an adequate heat management is essential to couple these reactors with other units of the power plant. Heat management refers to the dynamic operation of fixed bed reactors to achieve the required solid temperature and conversion and to produce the gaseous streams at the optimal operating conditions for the studied power plant. Two different reactor cycle strategies have been analyzed: (i) Oxidation/Heat Removal/Purge/Reduction/Purge with different air inlet temperatures for different solid active material contents in the oxygen carrier; (ii) Oxidation/Purge/ Reduction/Heat Removal with inert gas. The effect of Water Gas Shift (WGS) activity of the oxygen carrier has also been discussed considering the most relevant technical and economic aspects. Due to the low rate of solid conversion of ilmenite with CO-rich syngas during the reduction cycle and due to the change in temperature of the produced gases, the first cycle strategy is not feasible for a continuous operation in a power plant, while the second cycle strategy appears very interesting for implementation of the CLC process using packed bed reactors with ilmenite as oxygen carrier in power plants.
\end{abstract}

(c) 2013 Elsevier B.V. All rights reserved.

\footnotetext{
* Corresponding author. Tel.: +31 40247 2241; fax: +31 402475833.

E-mail address: m.v.SintAnnaland@tue.nl (M. van Sint Annaland).
}

\section{Introduction}

The increase of carbon dioxide emissions due to human activities is amply recognized as one of the most important reasons for climate change. It is nowadays well accepted that carbon capture 


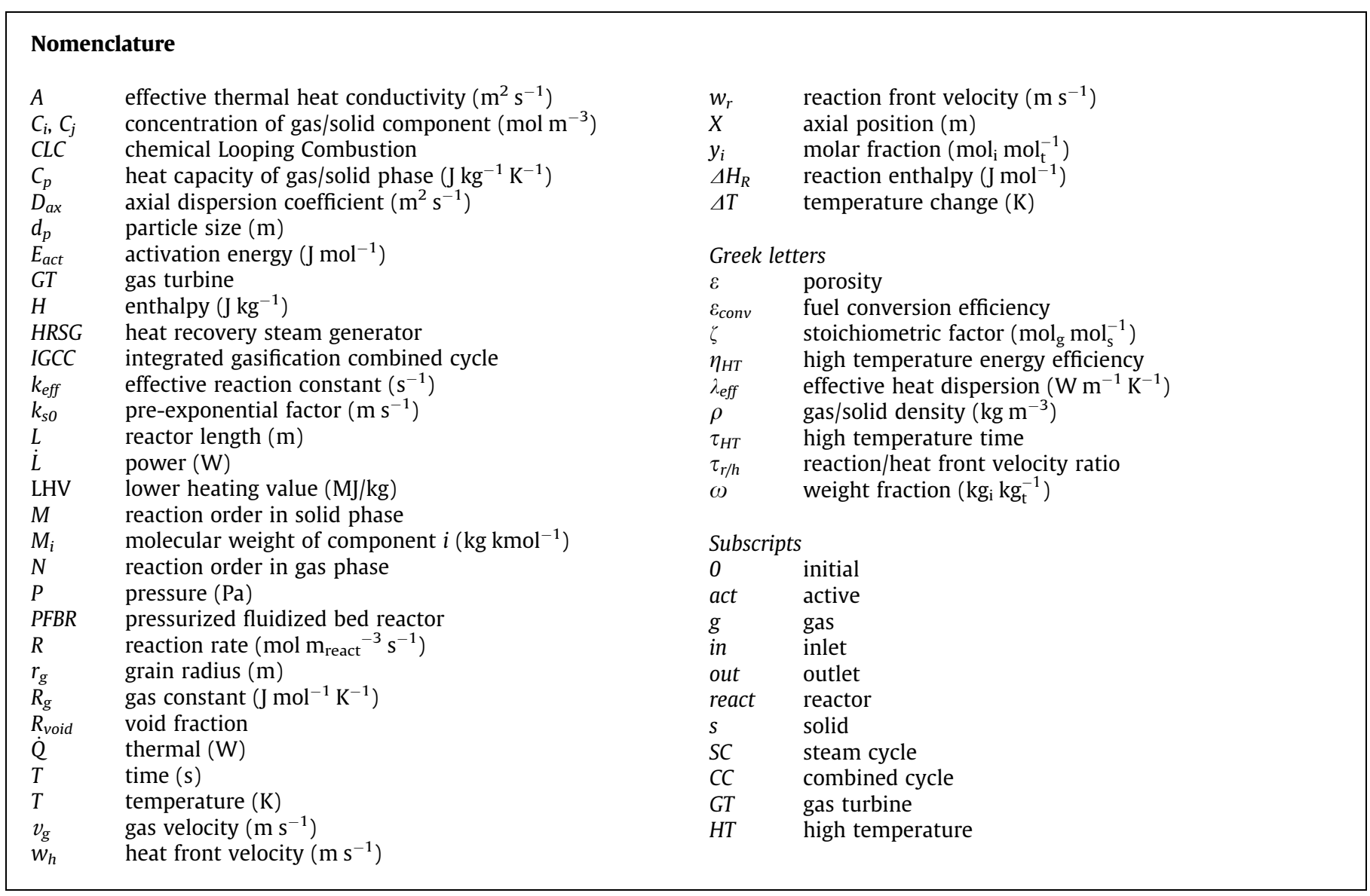

and storage (CCS) can be one of the most promising short/mediumterm technologies and a feasible solution for the reduction of anthropogenic $\mathrm{CO}_{2}$ emissions. About $40 \%$ of the emitted $\mathrm{CO}_{2}$ [1] is released from large scale power plants using fossil fuels, which represent at the same time the most important energy sources. In the last decades, several studies have been initiated to investigate the integration of CCS in existing power plants. Conventional technologies for large scale power production with near zero emissions of $\mathrm{CO}_{2}$ are often classified into post-combustion, pre-combustion and oxyfuel combustion processes. All these technologies lead to an energy efficiency penalty that can reach to $10-15$ percentage points depending on the technology adopted [2,3].

A novel technology for energy production that shows great potential to integrate low $\mathrm{CO}_{2}$ emissions with lower energy penalties is Chemical Looping Combustion (CLC). CLC is based on the use of an intermediate oxygen carrier that can be alternatively reduced and oxidized in order to produce $\mathrm{CO}_{2}$ undiluted with nitrogen, so that pure $\mathrm{CO}_{2}$ sequestration can be easily carried out after water condensation. When an oxidant stream (i.e. air) is fed to a reduced metal the solid oxidation is strongly exothermic and the heat generated is used for power production, while the metal reduction can be either exothermic or endothermic depending on the type of oxygen carrier and on the hydrocarbon fuel or syngas composition.

The generic reactions are:

Oxidation:

$\mathrm{Me}+\frac{1}{2} \mathrm{O}_{2} \rightarrow \mathrm{MeO}$

Reduction:

$\mathrm{MeO}+\mathrm{H}_{2} \rightarrow \mathrm{Me}+\mathrm{H}_{2} \mathrm{O}$
$\mathrm{MeO}+\mathrm{CO} \rightarrow \mathrm{Me}+\mathrm{CO}_{2}$

CLC technology is very attractive and competitive with other CCS technologies for large scale power plants, provided that the process can be operated at elevated pressures ( $>20$ bar) and high temperatures if operated with gaseous fuel (such as natural gas) $\left(>1200{ }^{\circ} \mathrm{C}\right)[9,10]$.

Power plants with CLC carbon capture can be fed with syngas from coal gasification and gas treating units. After the reduction cycle, the resulting high temperature $\mathrm{CO}_{2}$ and $\mathrm{H}_{2} \mathrm{O}$ from syngas conversion is cooled down producing high pressure steam. After water condensation the pressurized $\mathrm{CO}_{2}$ is compressed to supercritical condition (i.e. 110-150 bar) for the final storage. To assure sufficiently fast kinetics of the reaction between syngas and oxygen carrier during the reduction cycle the solid temperature needs to be sufficiently high.

During the oxidation phase, air is supplied by the gas turbine compressor (at the typical pressure of 20 bar, the temperature is close to $450^{\circ} \mathrm{C}$ ). Due to the exothermic reaction between oxygen carrier and air, a gas stream at constant high temperature and constant mass flow rate can be produced and sent to the gas turbine. After the expansion, the air exiting the GT at almost ambient pressure and high temperature (close to $500{ }^{\circ} \mathrm{C}$ ) is cooled down in a heat recovery steam generator to produce additional electricity and increase the power plant electrical efficiency. A simplified power plant layout is shown in Fig. 1.

Different configurations for the power cycle can also be envisaged, according to different system requirements that may lead to some penalty efficiency: e.g. if the air temperature at the compressor outlet is not high enough, air pre-heating requires high cost additional equipment, unusual for large scale gas turbines (such as gas-gas HT heat exchanger). 


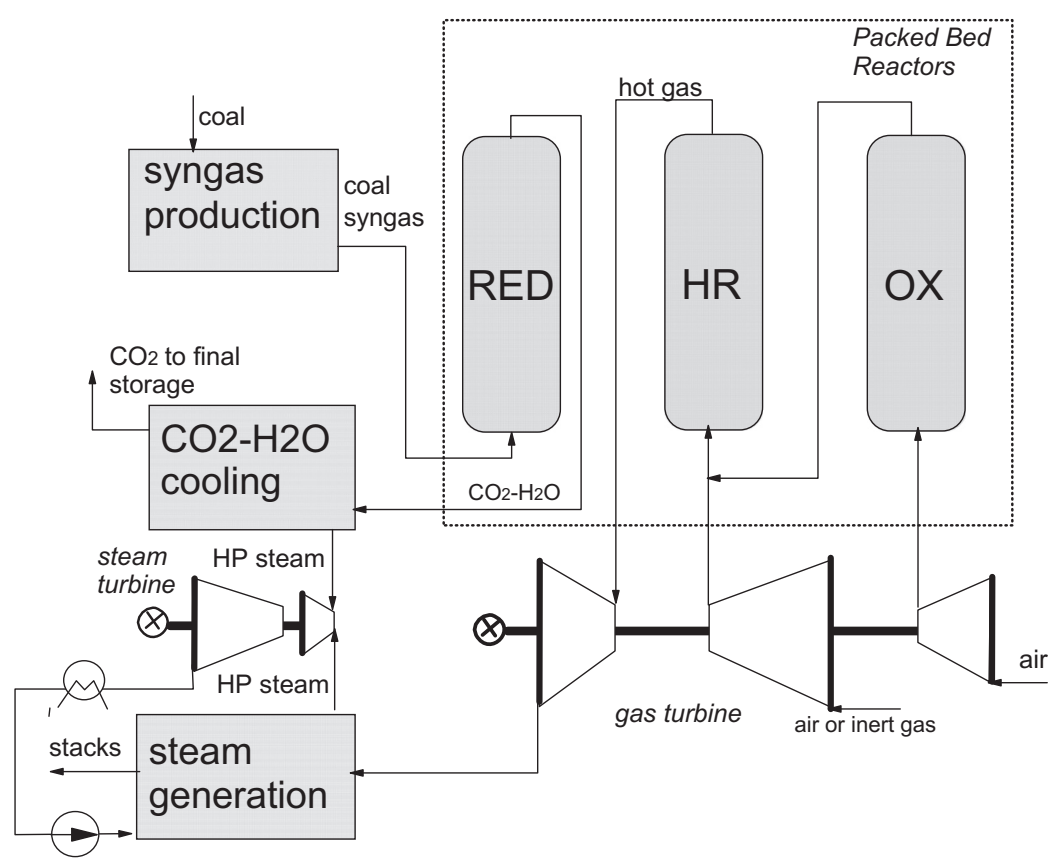

Fig. 1. Simplified coal-gasification power plant integrated with PBRs for $\mathrm{CLC}$ combustion and $\mathrm{CO}_{2}$ capture.

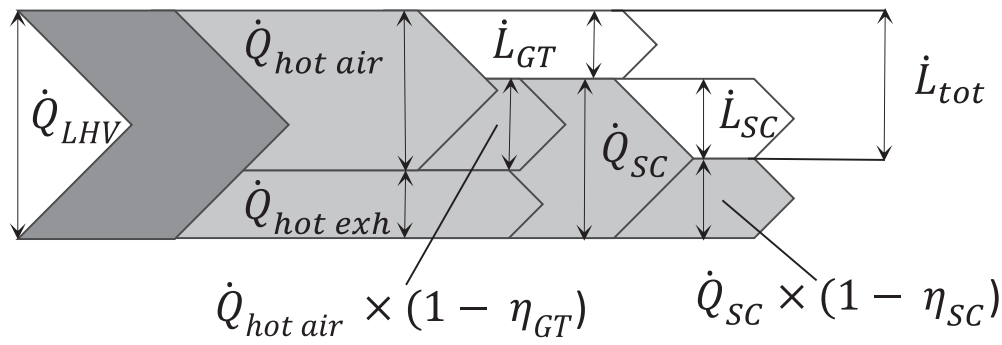

$$
\begin{aligned}
& \dot{Q}_{L H V}=\dot{Q}_{\text {hot air }}+\dot{Q}_{\text {hot exh }} \\
& \dot{L}_{G T}=\dot{Q}_{\text {hot air }} \times \eta_{G T} \\
& \dot{L}_{S C}=\underbrace{\left(\dot{Q}_{\text {hot air }} \times\left(1-\eta_{G T}\right)+\dot{Q}_{\text {hot exh }}\right) \times \eta_{S C}}_{\dot{Q}_{S C}} \\
& \dot{L}_{\text {tot }}=\dot{L}_{G T}+\dot{L}_{S C}=\dot{Q}_{\text {hot air }} \times\left(\eta_{C C}+\left(1-\eta_{G T}\right) \times \eta_{S C}\right)+\dot{Q}_{\text {hot exh }} \times \eta_{S C}
\end{aligned}
$$

$\eta_{C C}>\eta_{S C}$

Fig. 2. First law energy balance for a simplified power system operating with CLC technology.

In terms of plant performance, Fig. 2 presents a simplified first law energy balance of the fuel conversion: the heat of reaction is converted to exhaust gases $\left(\mathrm{CO}_{2}\right.$ and $\mathrm{H}_{2} \mathrm{O}$ and other species) and hot air. Hot air is sent to the gas turbine and the total amount of heat is converted partly in electricity with the electrical efficiency of a combined cycle $\eta_{c c}$, while the heat stored in the exhaust gases is converted into electricity by a steam cycle. The total efficiency of heat to electricity conversion in a combined cycle is normally higher than for a steam cycle. As a consequence, the higher the sensible heat handled by the gas turbine, the higher the overall electrical efficiency of the system.

The application of CLC has been studied especially with interconnected fluidized bed reactors working at atmospheric pressure for several applications and different oxygen carriers have been investigated [4]. The operability of interconnected CLC reactors working at atmospheric pressure has been demonstrated at different scales [5-8]. Circulating fluidized bed reactors can work in continuous operation producing an hot air stream stable in temperature and flow rate, but the solid circulation is difficult to be operated under pressurized conditions, especially as far as the loop sealing and the gas-solid separation (through cyclones) are concerned.

The technology discussed in this paper is based on the use of dynamically operated packed bed reactors with syngas from a coal gasification unit. The present investigation is part of the FP7 DemoCloCk European project: The objective of the project is to 


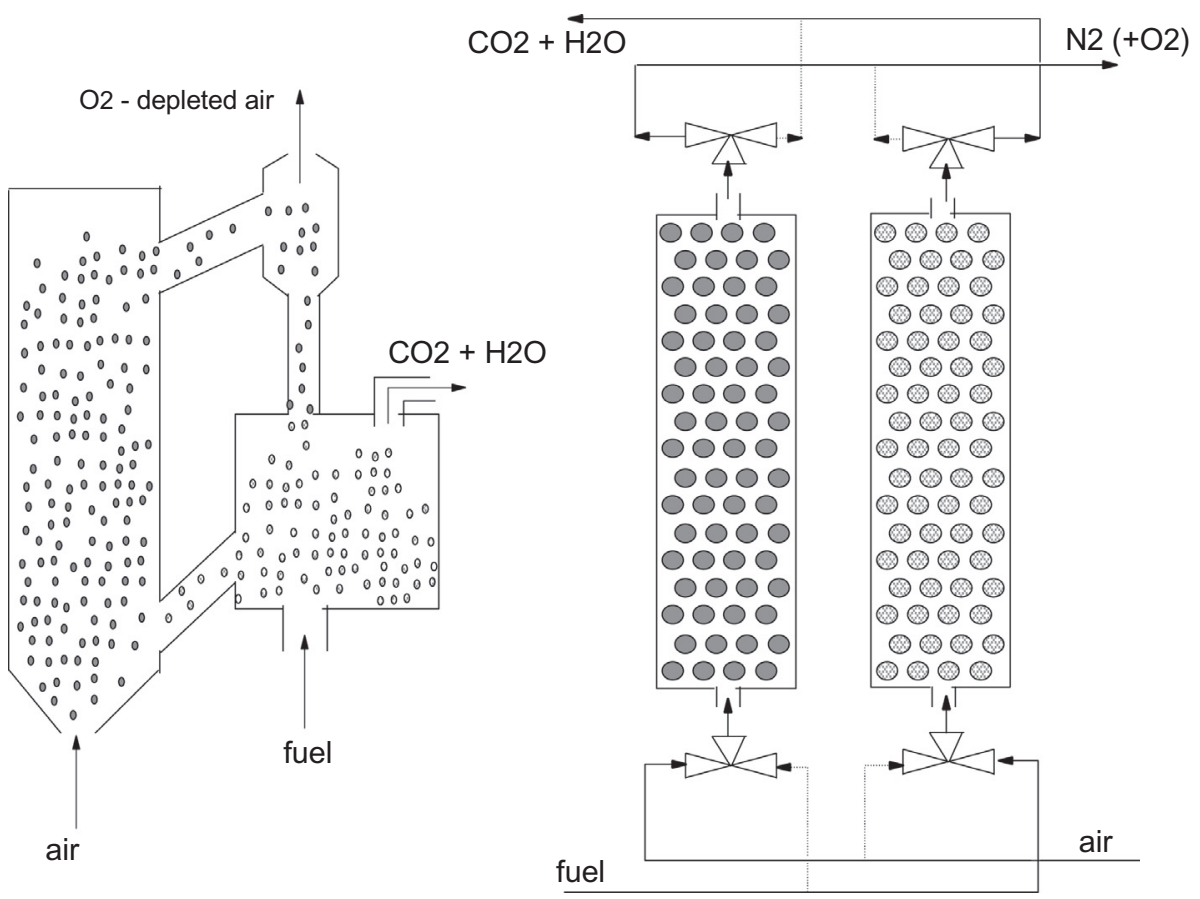

Fig. 3. Schematic representation of the CLC process with interconnected fluidized bed reactors (left) and parallel dynamically operated packed bed reactor (right).

demonstrate the technical, economic and environmental feasibility for implementing packed bed reactors operating at high temperature and high pressure in a CLC process for large-scale power plants.

Contrary to interconnected fluidized bed reactors, in packed bed reactors the solid remains stationary and the oxygen carrier is alternately exposed to oxidizing and reducing conditions (Fig. 3) [11]. Since solid recirculation (and thus gas-solid separation) is not required, pressurized conditions do not present critical issues.

Packed bed reactors for CLC are dynamically operated and the gas stream temperature at the outlet of the reactors - especially during the solid oxidation cycle - change with time [11]. To efficiently integrate this technology into a power plant, an adequate heat management of the reactors is extremely important. In particular, an important boundary condition dictated by the power island has to be taken into account: the hot stream needs to be produced at nearly constant temperature and mass flow rate, to preserve the gas turbine expander from thermal/mechanical cycling stress and from fluid-dynamic instability. On the other hand, an efficient operation of the packed beds imposes that: (i) solid conversion needs to be almost complete in order to increase the reactor capacity; (ii) kinetics of gas/solid reactions have to be fast enough in order to avoid fuel slip; (iii) hot spots are not allowed to avoid deactivation of solid material or the reactor materials could be damaged. These requirements put the packed bed reactor technology for CLC in front of relevant technical challenges, to assess their feasibility and competitiveness with other CCS technologies.

The present paper will discuss the proper heat management strategy for packed bed reactors for CLC of syngas. First, a comprehensive description of the model is reported in order to highlight the equations behind the simulation code, used to carry out the numerical analysis and the reactor performance prediction. The selection of an appropriate oxygen carrier is here discussed and the motivations behind the different strategies adopted are outlined. Results are discussed in detail, considering the current state of the art of the technology, the effects of the system integration in the power plant and some fundamental economic issues.

\section{Materials and methods}

\subsection{Selection of bed material (oxygen carrier)}

So far, most of the development of oxygen carriers has been done aiming at the selection of materials suitable for application in interconnected fluidized bed reactors [12-15]. Some requirements and specifications are different when working with packed bed reactors (PBRs): since the solid material is continuously exposed to the fresh gas stream, the complete oxidation range of the particles is encountered; the stability of the material needs to be assured over its entire oxidation range and for many reduction/oxidation cycles. In addition, the particle diameter needs to be large enough to avoid excessive pressure drop or bed fluidization [16]. Bed fluidization may occur if the gas velocity is higher than the minimum fluidization velocity as reported in [31].

Several materials have been successfully tested as oxygen carriers for CLC processes. The oxygen carriers are often based on a transition state metal oxide, e.g. $\mathrm{CuO}, \mathrm{NiO}, \mathrm{CoO}, \mathrm{Fe}_{2} \mathrm{O}_{3}$ or $\mathrm{Mn}_{3} \mathrm{O}_{4}$, supported on different inert materials, such as $\mathrm{Al}_{2} \mathrm{O}_{3}, \mathrm{SiO}_{2}, \mathrm{TiO}_{2}$ or $\mathrm{ZrO}_{2}$. Some of these materials have been studied in packed beds with natural gas [17]. In this work syngas from a coal gasification plant is used as reducing fuel instead of $\mathrm{CH}_{4}$.

The present analysis is based on the use of ilmenite as oxygen carrier since the material is naturally available (thus inexpensive as raw material) and attractive for chemical looping combustion. Several studies have been carried out with ilmenite in a lab scale atmospheric fluidized bed to test the thermo-physical and chemical properties $[18,19]$. Ilmenite $\left(\mathrm{FeTiO}_{3}\right)$ as oxygen carrier has shown high conversions for syngas applications, where $\mathrm{CO}$ and $\mathrm{H}_{2}$ are the main components. The use of syngas (50\% CO and $50 \%$ $\mathrm{H}_{2}$ ) have been investigated by Azis et al. [20] with natural and synthetic ilmenite during the reduction phase, in order to highlight the effect on fuel conversion at $950^{\circ} \mathrm{C}$ with different Fe/Ti ratios; the mechanical properties of solid material have been studied as well. Adanez et al. [21] evaluated ilmenite activation after several cycles with syngas: fresh ilmenite and calcinated ilmenite reach the same level of activation at different times and the solid conversion is sta- 
bilized; the increasing in number of cycles reduces the initial oxygen transport capacity (from $4 \%$ to $2.1 \%$ ) while the solid conversion becomes higher until the reactivity is stable. The oxygen transport capacity of ilmenite has been calculated by Leion et al. [22] and compared with the theoretical oxygen transport capacity (5\%) using $15 \mathrm{~g}$ of ilmenite with a particle diameter of $125-180 \mu \mathrm{m}$ with methane and syngas $\left(50 \% \mathrm{CO}, 50 \% \mathrm{H}_{2}\right)$ in a laboratory-scale fluidized bed reactor. An extensive discussion on ilmenite as oxygen carrier for CLC has also been presented by Abad et al. [23] and the related reaction rates have been calculated for the oxidation and reduction cycles both for pre-oxidized and activated ilmenite: the reactivity of both solid materials have been investigated using $\mathrm{H}_{2}$, $\mathrm{CO}$ and $\mathrm{CH}_{4}$ as reducing gas at different temperatures (from $800{ }^{\circ} \mathrm{C}$ to $950{ }^{\circ} \mathrm{C}$ ) with different gas compositions. The main kinetic parameters for the reaction rates of ilmenite have been evaluated assuming multi grain model with chemical reaction control and considering a mixed-resistance between chemical reaction and diffusion in the solid products.

\subsection{Kinetic model}

The model used for the present investigation is based on a $1 \mathrm{D}$ adiabatic packed bed reactor model, reported in the following sections. Ilmenite has been selected as oxygen carrier. The kinetic model is based on gas-solids reaction between the gas components and the solid material. The main assumptions are reported here. Since no experimental data are available on the behavior of ilmenite in a packed bed reactor for chemical looping combustion, the kinetic model is based on the equations provided by Abad et al. [23]. The kinetic parameters have been confirmed with our TGA (thermogravimetric analysis) experiments (not reported in this paper) for a wide range of concentrations and temperatures. The gas-solid reactions for the oxidation and reduction cycle are:

Oxidation:

$2 \mathrm{FeTiO}_{3}+\frac{1}{2} \mathrm{O}_{2} \rightarrow \mathrm{Fe}_{2} \mathrm{TiO}_{5}+\mathrm{TiO}_{2}$

Reduction with $\mathrm{H}_{2}$ :

$\mathrm{Fe}_{2} \mathrm{TiO}_{5}+\mathrm{TiO}_{2}+\mathrm{H}_{2} \rightarrow 2 \mathrm{FeTiO}_{3}+\mathrm{H}_{2} \mathrm{O}$

Reduction with CO:

$\mathrm{Fe}_{2} \mathrm{TiO}_{5}+\mathrm{TiO}_{2}+\mathrm{CO} \rightarrow 2 \mathrm{FeTiO}_{3}+\mathrm{CO}_{2}$

Total reduction to $\mathrm{FeTiO}_{2}\left(\mathrm{Fe}+\mathrm{TiO}_{2}\right)$ has to be prevented because the pure iron presents: (i) low selectivity towards $\mathrm{CO}_{2}$ and $\mathrm{H}_{2} \mathrm{O}$ (resulting in higher fuel slip and thus lower $\mathrm{CO}_{2}$ capture efficiency), which is more important for the fluidized bed technology and (ii) the tendency to agglomerate into bigger Fe particles causing the deactivation of the oxygen carrier as well as clogging of the packed bed.

In this study it was assumed that the solid conversion does not include the intermediate solid states so that the active solid material goes from hematite $\left(\mathrm{Fe}_{2} \mathrm{O}_{3}\right)$ to wustite $(\mathrm{FeO})$, while titanium oxide is treated as inert material and does not take part in the chemical transformations.

Thermo-physical properties of solid species have been taken from [24].

It was also assumed that the reaction is completely selective to carbon dioxide and steam. According to the chemical equilibrium of the solid phase in the range of operation of the system, different iron species can be formed, during the continuous fresh syngas feeding to the solid material in the reduction cycle (see Fig. 4) as predicted via minimization of the total free Gibbs energy. The figure shows that also Fe could be formed, but experimental data from the TGA (not presented here) have shown that $\mathrm{Fe}$ is not formed after syngas feeding (also depending on the $\mathrm{CO}_{2}$ and $\mathrm{H}_{2} \mathrm{O}$

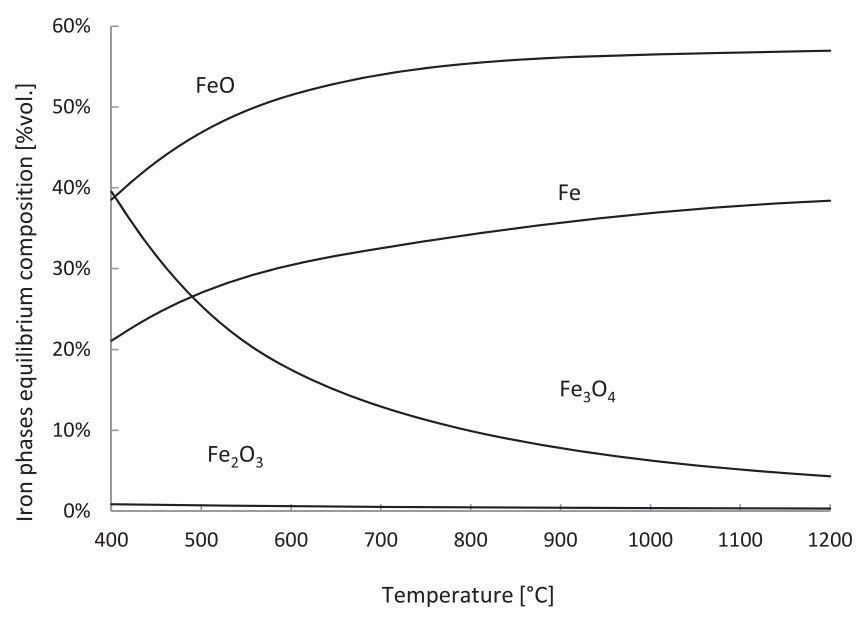

Fig. 4. Iron species equilibrium composition at different temperature (from $400{ }^{\circ} \mathrm{C}$ to $1200{ }^{\circ} \mathrm{C}$ ) reacting with syngas (composition from base case) at 20 bar.

concentrations); however, a more detailed kinetic model is needed to capture all these details.

The reaction rate $\left[\mathrm{mol} / \mathrm{m}_{\text {reactor }}^{3} \mathrm{~s}\right]$ is generally expressed as:

$r=\left(1-\varepsilon_{\text {bed }}\right) k_{e f f} C_{g, i}^{n} C_{s, j}^{m}$

where $C$ is respectively the gas/solid concentration in the reactor and $\varepsilon_{\text {void }}$ is the bed void fraction (assumed to be equal to 0.4 ).

The reaction kinetic rate constants $k_{\text {eff }}$ were estimated as function of the temperature using the Arrhenius equation:

$k_{\text {eff }}=\frac{k_{s o, i}}{r_{g}} \exp \left(\frac{-E_{a c t, i}}{R_{g} T}\right)$

The grain radius $r_{g}$ was selected equal to $1.25 \mu \mathrm{m}$ [23]. The kinetic parameters for the gas solid reactions have been summarized in Table 1.

The effect of carbon deposition has not been included in this work, but according to the chemical equilibrium with the syngas composition considered in this study, graphite could be formed in the range of $400-800{ }^{\circ} \mathrm{C}$. Additional studies related to the carbon formation kinetics over ilmenite would be required, for different syngas compositions, but this issue has been considered outside the scope of this investigation.

\subsection{Reactor model}

A simplified analytical approach is briefly described here, to provide an overview of the packed bed reactor behavior and of its potential for application in CLC.

In principle, the production of a constant high temperature gas stream during the oxidation cycle is possible with dynamically operated packed bed reactors. If an ideal system is considered in which the non-catalytic gas-solid reaction proceeds fast and dispersion effects are neglected (and thus assuming an ideal plug flow model), the evolution of the axial concentration profile of the gaseous stream (oxygen) and the temperature evolution can be predicted, as shown in Fig. 5, and amply discussed in [11,25].

Table 1

Kinetic parameters used in the present study (from [23]).

\begin{tabular}{llll}
\hline & $\mathrm{H}_{2}$ & $\mathrm{CO}$ & $\mathrm{O}_{2}$ \\
\hline$k_{\mathrm{s} 0}\left(\mathrm{~mol}^{1-n} \mathrm{~m}^{3 n-2} \mathrm{~s}^{-1}\right)$ & $6.2 \times 10^{-2}$ & $1.0 \times 10^{-1}$ & $1.9 \times 10^{-3}$ \\
$E_{\text {act }}\left(\mathrm{kJ} \mathrm{mol}^{-1}\right)$ & 65 & 80.7 & 25.5 \\
$n$ & 1 & 0.8 & 1 \\
\hline
\end{tabular}




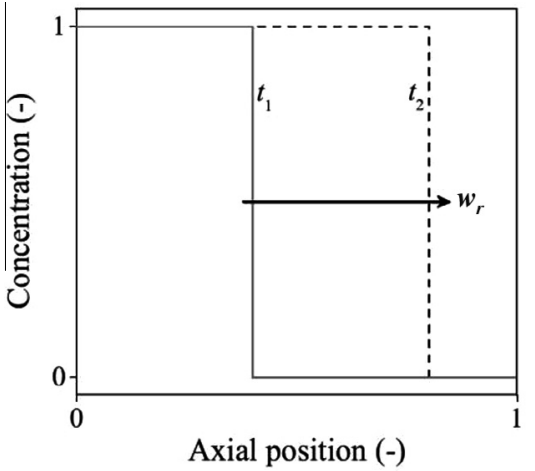

(a) Concentration profile

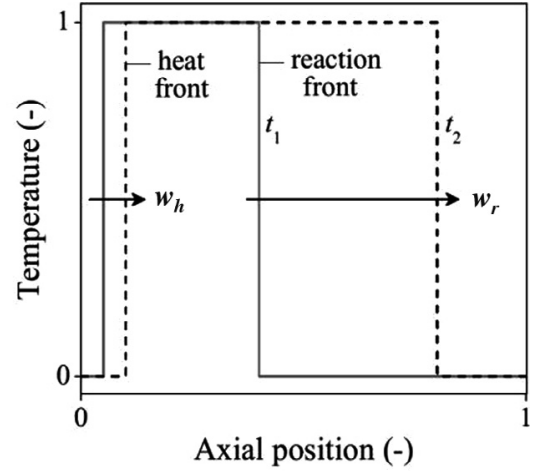

(b) Temperature profile

Fig. 5. Schematic representation of the evolution of the (dimensionless) axial profile of (a) the gaseous reactant concentration and (b) the temperature.

Since the gas-solid reaction may continue until the particle is not completely converted, a reaction and heat front propagate with velocity $w_{r}$ and $w_{h}$ respectively through the bed (Fig. 5a) where $w_{r}>w_{h}$. As a result of the heat of reaction, the temperature of the bed changes during the complete cycle and both reaction and heat front can be depicted in the temperature profile (Fig. 5b). The steepness of the temperature fronts depends on the heat Péclet number $\mathrm{Pe}_{h}$ which represents the ratio between the convective heat flow and effective axial heat dispersion. The lower the $P e_{h}$ number, the smoother the change in temperature in the reaction front.

If the kinetics is fast enough, an overall energy balance can be formulated for the system, neglecting the volumetric heat capacity of the gas phase relative to the solid phase, assuming that the solid initial temperature is equal to the inlet gas temperature $\left(T_{0}\right)$ and that the final solid temperature is denoted by $T_{1}$ :

$\frac{\rho_{g} v_{g} \omega_{g, i}^{i n}}{M_{g, i}}\left(\Delta H_{r, i}\right)=\epsilon_{s} \rho_{s} C_{p, s}\left(w_{r}-w_{h}\right)\left(T_{1}-T_{o}\right)$

The heat front velocity can be calculated by assuming that the heat transfer from the solid to the gas is concentrated along the front. The reaction front velocity can be calculated assuming that all the gaseous reactant reacts with a known, stoichiometric amount of solid material: $w_{r}=\frac{\rho_{g} v_{g} \omega_{g, i}^{i n} M_{a c t}^{0}}{\epsilon_{s} \rho_{s} \omega_{a c t}^{0} M_{g, i} \zeta}$

$w_{h}=\frac{\rho_{g} v_{g} C_{p, g}}{\epsilon_{s} \rho_{s} C_{p . s}}$

So the ratio $\tau_{r / h}$ between the reaction and heat front velocity is equal to:

$\tau_{r / h}=\frac{w_{r}}{w_{h}}=\frac{\omega_{g, i}^{i n} M_{a c t}^{0} C_{p, s}}{C_{p, g} \omega_{a c t}^{0} M_{g, i} \zeta}$

As it can be seen, the ratio $\tau_{r / h}$ is almost linearly dependent (Fig. 6) on the active content in the gas phase: the higher the concentration of reactant in the gas stream, the faster the reaction front velocity and the longer the reactor length between the reaction front and the heat front, which is at nearly constant conditions (temperature $T_{1}$ and mass flow rate). $\tau_{r / h}$ is typically higher than 1 , but Fernandez et al. [30] recently discussed PBR applications of $\mathrm{Ca}-\mathrm{Cu}$ chemical loop with a lower value.

The packed bed reactor model used in this work has been developed and discussed in recent papers [23]. An extensive discussion is also carried out about the effect of the particle model [26] and the combined effect of the reactor model and the particle model in [11]. A parametric analysis was also performed to investigate

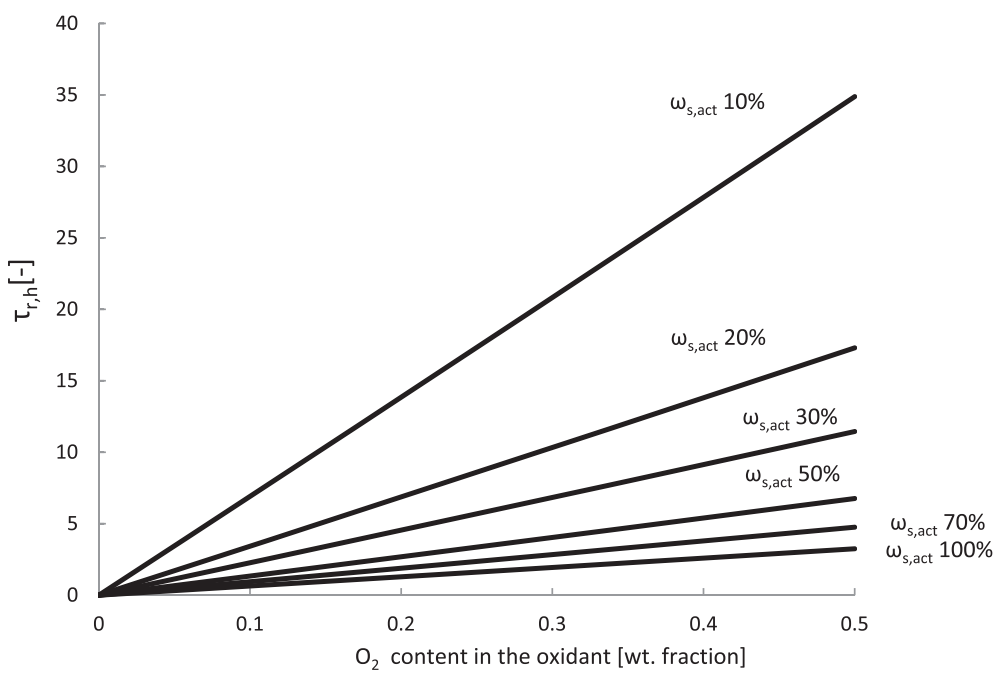

Fig. 6. $\tau_{r} / h$ for the oxidation reaction as function of oxygen content according to the simplified model. 
the effect of different operating conditions in the reactor model [17]. The present models have been validated with experiments using copper oxide as oxygen carrier.

The difference between the present paper and the previous ones is that, in the previous works, the model has been used to evaluate the behavior of the packed bed in a single cycle (oxidation or reduction), starting from an ideal condition in which the temperature of the bed is uniform and equal to the feed temperature of the gaseous stream. In the present study, the model is used to evaluate consecutive cycles, with a bed temperature at the beginning of each cycle which is the result of the previous cycle; moreover, this temperature is very different from the temperature of the incoming gaseous stream. Therefore, the real behavior of the packed bed is simulated, by reproducing the complete process consisting of multiple oxidations, reduction and heat removal.

The main assumptions and the governing equations for the reactor model are: (i) radial temperature or concentration gradients are neglected; (ii) the heat transfer limitations from gas to solid phase is accounted for in the effective heat dispersion (pseudohomogeneous model); (iii) heat losses through the reactor wall are neglected; (iv) pressure drops are fully accounted for and calculated with Ergun's equation. The governing equations of the mass and energy balances for the reactor model are reported in Table 2, while the constitutive equations for the description of heat and mass dispersions are reported in Table 3. A very efficient finite difference technique with higher order temporal and spatial discretization with local grid and time step adaption has been used [27].

\subsection{Cycle strategies}

The packed bed reactors for CLC are dynamically operated, with a reduction step starting in a bed with a temperature profile resulting from the previous step. Thus, heat management plays an important role in terms of bed temperature profiles and gas conditions at the reactor outlet. The aim of this investigation is mainly based on the development of a process with reduced energy penalty efficiency with respect to a conventional IGCC with no $\mathrm{CO}_{2}$ capture.

As already mentioned, packed bed reactors can be used in a power plant because, during the oxidation cycle, the velocity of

Table 2

Governing equations in the reactor model.

\begin{tabular}{lc}
\hline $\begin{array}{l}\text { Reactor model (axial } \\
\text { direction) }\end{array}$ & \\
\hline Gas phase balance & $\varepsilon_{g} \rho_{g} \frac{\partial \omega_{g, i}}{\partial t}=-\rho_{g} v_{g} \frac{\partial \omega_{g, i}}{\partial x}+\frac{\partial}{\partial x} \rho_{g} D_{a x} \frac{\partial \omega_{g, i}}{\partial x}+\varepsilon_{g} r_{i} M_{i}$ \\
Solid phase balance & $\varepsilon_{s} \rho_{s} \omega_{a c t}^{0} \frac{\partial \omega_{s, j}}{\partial t}=-\varepsilon_{g} r_{i} M_{i}$ \\
Energy balance & $\left(\varepsilon_{g} \rho_{g} C_{p, g}+\varepsilon_{s} \rho_{s} C_{p, s}\right) \frac{\partial T}{\partial t}$ \\
& $=-\rho_{g} v_{g} C_{p g} \frac{\partial T}{\partial x}+\frac{\partial}{\partial x} \lambda_{a x} \frac{\partial T}{\partial x}+\varepsilon_{g} r_{i} \Delta H_{R, i}$ \\
Continuity equation & $r_{i}=\left(1-\varepsilon_{\text {void }}\right) k_{e f f} C_{g, i}^{m} C_{s, i}^{n}$ \\
\hline
\end{tabular}

Table 3

Constitutive equations for the description of heat and mass dispersions.

\begin{tabular}{|c|c|}
\hline Reactor model (axial direction) & \\
\hline Effective axial heat dispersion & $\lambda_{a x}=\lambda_{\text {bed }, 0}+\frac{R e P r \lambda_{g}}{P e_{a x}}+\frac{R e^{2} P r^{2} \lambda_{g}}{6\left(1-\varepsilon_{g}\right) N u}$ \\
\hline Heat Péclet axial number & $P e_{a x}=\frac{2\left(0.17+0.33 \exp \left[\frac{24}{R}\right]\right)}{1-\left(0.17+0.33 \exp \left[\frac{-24]}{R e}\right]\right)}$ \\
\hline Nusselt number & $\begin{array}{l}N u=\left(7-10 \varepsilon_{g}+5 \varepsilon_{g}^{2}\right)\left(1+0.7 \operatorname{Re}^{0.2} \operatorname{Pr}^{1 / 3}\right) \\
\quad+\left(1.33-2.4 \varepsilon_{g}+1.2 \varepsilon_{g}^{2}\right) \operatorname{Re}^{0.7} \operatorname{Pr}^{1 / 3}\end{array}$ \\
\hline Axial mass dispersion & $D_{a x}=\left(\frac{0.73}{\operatorname{ReSc}}+\frac{0.5}{\varepsilon_{g}+\frac{9.7 \varepsilon_{g}^{2}}{\operatorname{Re} s c}}\right) v_{g} d_{p}$ \\
\hline
\end{tabular}

the reaction front $w_{r}$ is much larger than the velocity of heat front $w_{h}$ : once the bed is totally oxidized, the solid material is heated to a very high temperature and a high amount of heat is stored in the reactor. Starting with a constant solid temperature, after the oxidation cycle, the bed temperature is almost constant, so a gas stream can be used to remove the stored heat (heat removal cycle) producing a gas stream at almost constant high temperature and pressure that can be fed to an efficient thermodynamic cycle to produce electricity.

After the packed bed is cooled (heat is removed), the reduction cycle can start to reduce the solid material. However, the temperature profile at the beginning of reduction cycle strongly affects the system performance: if this temperature is too low, the kinetics of the reduction reactions will be too slow and the fuel will not be fully oxidized, so the exhaust gases will contain $\mathrm{CO}$ and $\mathrm{H}_{2}$ (fuel slip) and the $\mathrm{CO}_{2}$ separation will not be efficient in terms of energy requirement and exhaust gas purity.

According to the kinetic model previously described, where the activation energy for carbon monoxide conversion is high, a relatively high temperature is required to convert $\mathrm{CO}$ to $\mathrm{CO}_{2}$.

Two main different heat management strategies are here proposed, referred to as strategy $A$ and $B$. In cycle strategy $A$ the complete cycle is performed as reduction/purge/oxidation/heat removal/purge and four different cases have been considered (Fig. 7).

Strategy A.1: air is fed at different temperatures $\left(450{ }^{\circ} \mathrm{C}, 600^{\circ} \mathrm{C}\right.$, $\left.750{ }^{\circ} \mathrm{C}\right)$. The solid composition is chosen in order to obtain a maximum solid temperature equal to $1200^{\circ} \mathrm{C}$ after the oxidation cycle.

Strategy A.2: the process is the same as in strategy A.1, but with a decreased solid active weight content (10\%) in the oxygen carrier.

Strategy A.3: due to the higher temperature in the last part of the bed at the end of oxidation cycle, in this configuration the syngas is fed from the opposite side than the air feed (i.e. counter-current operation), while the cycle sequence is still reduction, purge, oxidation, heat removal, purge.

Strategy A.4: The oxygen carrier may have a certain water gas shift activity as recently discussed in Schewebel et al. [29]. The main problem on the kinetic reactions is the $\mathrm{CO}$ oxidation at low temperature $\left(\mathrm{H}_{2}\right.$ has a high reaction rate even at $\left.450{ }^{\circ} \mathrm{C}\right)$. If the syngas has high $\mathrm{CO}$ and $\mathrm{H}_{2} \mathrm{O}$ content, the Water Gas Shift (WGS) reaction may occur as a heterogeneous reaction, according to

$\mathrm{CO}+\mathrm{H}_{2} \mathrm{O} \rightarrow \mathrm{H}_{2}+\mathrm{CO}_{2} \Delta H_{298 K}^{0}=-41.1 \mathrm{~kJ} / \mathrm{kmol}$

Water Gas Shift is a slightly exothermic reaction commonly used for syngas upgrading or hydrogen production and several works have been published about the catalyst properties [28]. In the conventional process the reaction occurs in two different main stages: HT-WGS $\left(310-450^{\circ} \mathrm{C}\right)$ where ferrochrome catalysts are commonly used in the industrial scale and LT-WGS $\left(200-250{ }^{\circ} \mathrm{C}\right)$ where a mixture of $\mathrm{ZnO}, \mathrm{CuO}$ and $\mathrm{Cr}_{2} \mathrm{O}_{3} / \mathrm{Al}_{2} \mathrm{O}_{3}$ is used as catalyst: the first stage is used to increase the kinetics of the reaction using the high temperatures, while the second stage allows an higher CO conversion (because of thermodynamic limitations). In a CLC reactor the solid material experiences different temperatures between the reduction and oxidation cycle (i.e. $450-1200^{\circ} \mathrm{C}$ ). Since the operating temperatures for the system here considered is not conventional (for WGS), the catalyst properties for WGS have not yet been discussed, which are behind the purpose of the present investigation. A sensitivity analysis is carried out considering the fuel conversion due to the WGS as a fraction of the WGS chemical equilibrium conversion (respectively $5-15-25-50 \%$ of the equilibrium conversion). The present analysis is considered in order to assess the effect of using a solid material with WGS activity.

In cycle strategy B the reactors are operated respectively in Reduction, Heat Removal with an inert gas stream, solid oxidation until the reaction front reaches the end of the reactor and purge cycles (strategy B.1). With this process it is possible to carry out the 

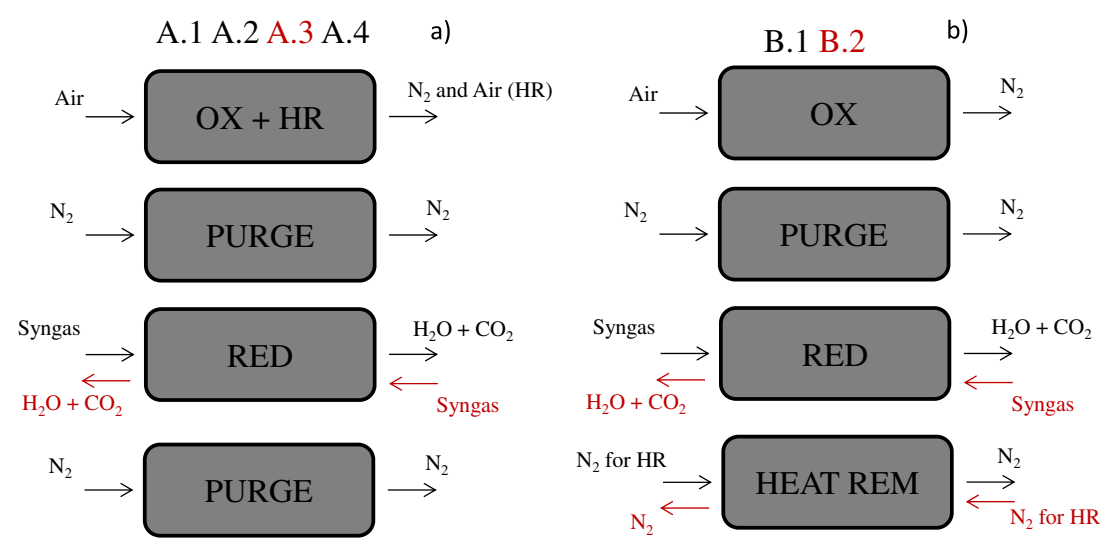

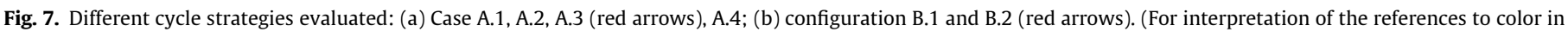
this figure legend, the reader is referred to the web version of this article.)

reduction cycle when almost the entire bed is at the maximum temperature so that the reduction reaction rates are high and the fuel conversion occurs faster; In this case it is not possible to use air to remove the heat stored in the solid in the bed because the heat removal is carried out with the solids in the reduced state. Pure nitrogen has been selected as gas stream for this cycle. Increasing the reaction temperature during the reduction cycle, the possibility to form $\mathrm{Fe}$ increases and the $\mathrm{Fe}_{3} \mathrm{O}_{4}$ decreases. However, we assumed that iron is not present even at $1200^{\circ} \mathrm{C}$, as assumed by Abad et al. [23] for an operating temperature of $950{ }^{\circ} \mathrm{C}$.

Strategy B.2: the process is the same as in strategy B.1, but the syngas and the inert gas for the heat removal are fed counter-cur- rent by to the reactor. With this configuration the exhaust gases leave the reactor at lower temperature and more heat is available for the inert gas used in the heat removal cycle.

The reactor geometry has been fixed and the main assumptions for the different simulations have been listed in the

Table 4 . The cycle time has been chosen according to the reduction cycle at a fixed amount of reactive species $\left(\mathrm{CO}\right.$ and $\left.\mathrm{H}_{2}\right)$ in order to obtain an almost full solid reduction (about $95 \%$ of the total solid active phase during the reduction cycle).

The same cycle time has been chosen for the oxidation/heat removal/pure oxidation cycles to make the comparison between the configurations easier. However, the time of each single cycle can be

Table 4

Main Assumptions for the analysis of selected configurations.

\begin{tabular}{|c|c|c|c|c|c|c|c|}
\hline Assumptions & A1 450 & A1 600 & A1 750 & A2 & A4 & B1 & B2 \\
\hline \multicolumn{8}{|l|}{ Syngas } \\
\hline Syngas dry composition (vol.\%) & \multicolumn{7}{|c|}{$\mathrm{H}_{2} 22 \%, \mathrm{CO} 60.5 \%, \mathrm{H}_{2} \mathrm{O} 0.3 \%, \mathrm{CO}_{2} 2.1 \%, \mathrm{~N}_{2} 14.7 \%$} \\
\hline Syngas dry mass flow rate $(\mathrm{kg} / \mathrm{s})$ & \multicolumn{7}{|c|}{0.051} \\
\hline $\mathrm{H}_{2} \mathrm{O}$ dilution $(\mathrm{kg} / \mathrm{s})$ & \multicolumn{7}{|l|}{0.027} \\
\hline Syngas inlet Temperature $\left({ }^{\circ} \mathrm{C}\right)$ & \multicolumn{7}{|l|}{450} \\
\hline Syngas inlet pressure (bar) & \multicolumn{7}{|l|}{20} \\
\hline Cycle time $(\mathrm{s})$ & 300 & 250 & 200 & 88 & 300 & 300 & 300 \\
\hline \multicolumn{8}{|l|}{ Air } \\
\hline Air composition (vol.\%) & \multicolumn{7}{|c|}{$\mathrm{O}_{2} 21 \%, \mathrm{~N}_{2} 79 \%$} \\
\hline Air mass flow rate $(\mathrm{kg} / \mathrm{s})$ & 0.57 & 0.69 & 0.81 & 0.44 & 0.57 & 0.1 & 0.1 \\
\hline Air inlet temperature $\left({ }^{\circ} \mathrm{C}\right)$ & 450 & 600 & 750 & 450 & 450 & 450 & 450 \\
\hline Air inlet pressure (bar) & 20 & & & & & & \\
\hline Cycle time (s) & 300 & 250 & 200 & 300 & 300 & 300 & 300 \\
\hline \multicolumn{8}{|l|}{ Nitrogen (strategies B1 $\& B 2$ ) } \\
\hline $\mathrm{N}_{2}$ composition (vol.\%) & & & & & & $\mathrm{N}_{2} 1 \mathrm{C}$ & \\
\hline $\mathrm{N}_{2}$ inlet pressure (bar) & & & & & & 20 & \\
\hline $\mathrm{N}_{2}$ inlet Temperature $\left({ }^{\circ} \mathrm{C}\right)$ & & & & & & 450 & \\
\hline $\mathrm{N}_{2}$ mass flow rate $(\mathrm{kg} / \mathrm{s})$ & & & & & & 0.4 & 0.55 \\
\hline Cycle time $(\mathrm{s})$ & & & & & & 300 & 300 \\
\hline \multicolumn{8}{|l|}{ Purge gas } \\
\hline Purge gas composition (vol.\%) & \multicolumn{7}{|c|}{$\mathrm{N}_{2} 100 \%$} \\
\hline Purge gas mass flow rate $(\mathrm{kg} / \mathrm{s})$ & \multicolumn{7}{|c|}{$0.2(5 \times$ reactor volume in $10 \mathrm{~s})$} \\
\hline Purge gas inlet temperature $\left({ }^{\circ} \mathrm{C}\right)$ & \multicolumn{7}{|c|}{450} \\
\hline Purge gas inlet pressure (bar) & \multicolumn{7}{|l|}{20} \\
\hline Cycle time (s) & \multicolumn{7}{|l|}{10} \\
\hline \multicolumn{8}{|l|}{ Reactor geometry } \\
\hline Reactor length (m) & \multicolumn{7}{|l|}{2.5} \\
\hline Reactor diameter (m) & \multicolumn{7}{|l|}{0.3} \\
\hline \multicolumn{8}{|l|}{ Solid material } \\
\hline Active weight content (\%of $\mathrm{Fe}_{2} \mathrm{O}_{3}$ ) & $33 \%$ & $28 \%$ & $22 \%$ & $10 \%$ & $33 \%$ & $33 \%$ & $33 \%$ \\
\hline \multicolumn{8}{|l|}{ Oxidation } \\
\hline Active weight content (\%of FeO) & $31 \%$ & $26 \%$ & $20 \%$ & $9 \%$ & $31 \%$ & $31 \%$ & $31 \%$ \\
\hline Particle diameter $(\mathrm{mm})$ & 3 & & & & & & \\
\hline Solid porosity & $40 \%$ & & & & & & \\
\hline
\end{tabular}


fixed according with the mass flow rates in order to minimize the number of reactors, the plant complexity and pressure drop.

Since the purge cycles have the main purpose to remove the unconverted species from the reactor between the oxidation and reduction cycle, the time cycle was chosen to be $10 \mathrm{~s}$ (it has been verified that this is enough to purge the reactor) and the mass flow rate was chosen in order to feed five times the total reactor volume as suggested from industrial practices.

Several multiple cycles have been simulated in order to reach a cyclic steady state condition for each strategy adopted: starting from an initial temperature profile and solid concentration profile, after a few cycles these profiles are stabilized and the same initial condition is obtained at the beginning of each multiple cycle; concerning the gas side, the steady-state condition is reached when the outlet of the reactor is the same at each stage of the related multiple cycle in terms of temperature and gas composition.

The dry syngas composition used has been selected from ELCOGAS Puertollano IGCC power plant where a system with a packed bed CLC reactor is going to be tested as experimental part of the research project FP7 DemoCLoCk.

The present investigation has been carried out with reference to a reactor for $0.3 \mathrm{~m}$ of diameter and $2.5 \mathrm{~m}$ of length filled with solid material with a particle diameter equal to $3 \mathrm{~mm}$. A sensitivity analysis has also been carried out for the best cases with a $\mathrm{CO}_{2}$-diluted syngas.

\section{Results and discussions}

The simulation results for the different cycle strategies are presented and discussed in terms of heat removal and energy efficiency of the cycle. The effect of inlet air temperature is first discussed in order to highlight its effect on the bed temperature and the solid conversion.

\subsection{Strategy A: reduction/purge/oxidation/heat removal/purge}

For the case A.1, the bed temperature profiles have been investigated with different air operating conditions. For the case A.1, the air flows were adjusted for the different inlet air temperatures in order to remove the heat produced during each cycle. After several multiple cycles (when the system has reached its cyclic steady state) the axial bed temperature profile was plotted at the beginning of the reduction cycle (Fig. 8). The initial bed temperature profile defines how the reaction front will proceed during the reaction. For the reduction cycle, the lower the initial bed temperature profile the lower the reaction rate.

The amount of active material has been selected to reach the maximum temperature $\left(1200^{\circ} \mathrm{C}\right)$ during the oxidation cycle according to the maximum temperature achievable for the solid material as discussed in [25]. At the beginning of the reduction cycle, the solid in the initial part of bed (between $60 \%$ and $70 \%$ of the reactor length) is at the same temperature of the inlet air (used during the heat removal cycle), while the other part is hotter, since the heat removal cycle does not remove completely the heat stored in the reactor. Comparing Figs. $8 \mathrm{a}-\mathrm{c}$, it can be observed that the higher the inlet air temperature, the higher the initial temperature for the reduction.

With these temperature profiles at the beginning of the reduction cycle, the solid conversion (amount of $\mathrm{Fe}_{2} \mathrm{O}_{3}$ converted in $\mathrm{FeO}$ ) at the end of the reduction cycle is plotted in Fig. 9a. Only when the air inlet temperature is $750{ }^{\circ} \mathrm{C}$ the packed bed reactor has a uniform (high) solid conversion during the reduction cycle, and the temperature profile during the oxidation cycle results in a constant high temperature stream which can be used effectively in a power cycle (Fig. 9b).
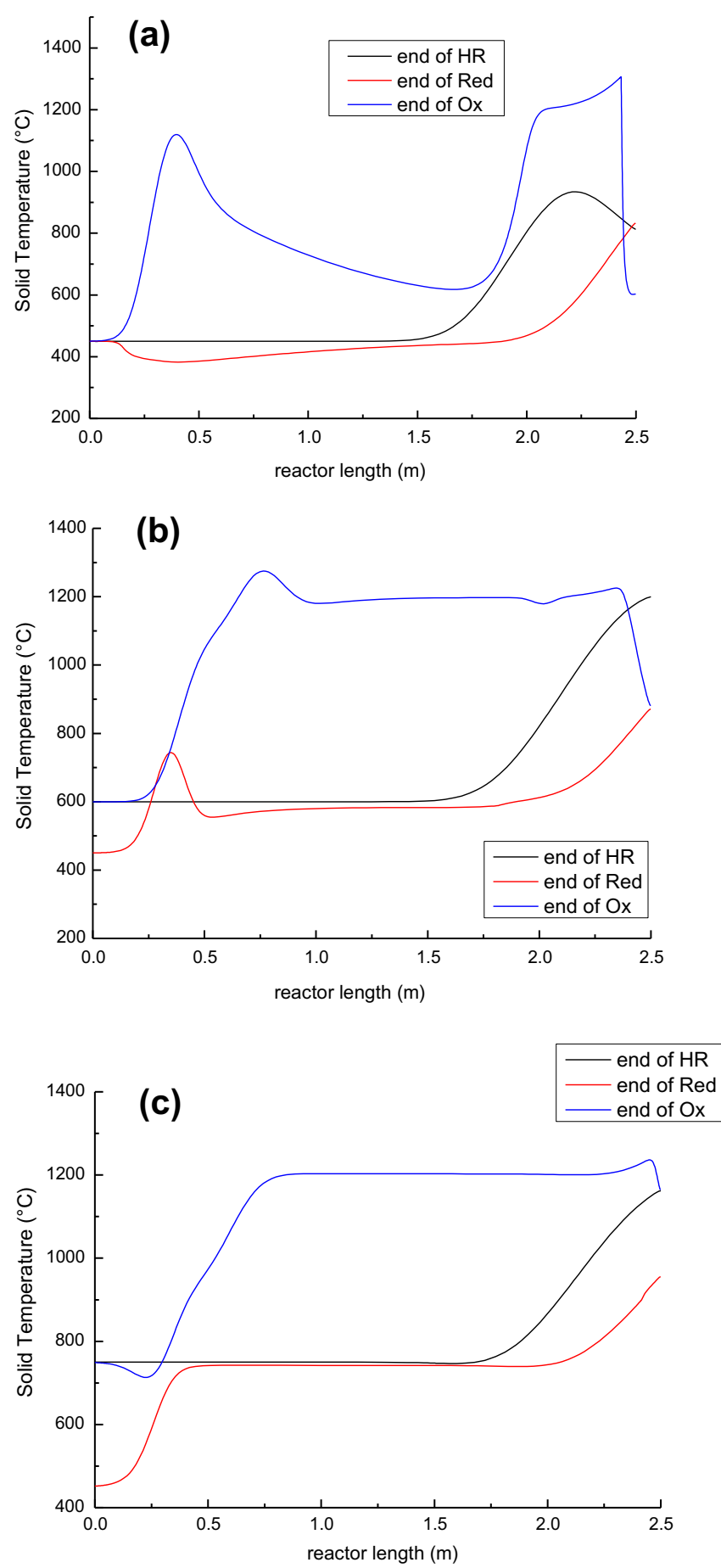

Fig. 8. Case A1 - axial solid temperature profiles at the end of the reduction cycle (red lines), at the end of oxidation cycle (blue lines) and the heat removal cycle (black lines) at $450{ }^{\circ} \mathrm{C}(\mathrm{a}), 600{ }^{\circ} \mathrm{C}(\mathrm{b}), 750{ }^{\circ} \mathrm{C}$ (c). (For interpretation of the references to color in this figure legend, the reader is referred to the web version of this article.)

For the cases with an air inlet temperature of $450{ }^{\circ} \mathrm{C}$ and $600{ }^{\circ} \mathrm{C}$, the solid conversion and the corresponding gas stream outlet conditions are not uniform. In particular, the lower the temperature the smaller the amount of oxygen carrier that is reduced (Fig. 9a). Moreover, fuel slip occurs very fast during the reduction cycle because the kinetics (especially for the $\mathrm{CO}$ ) is too slow, especially at $450{ }^{\circ} \mathrm{C}$ (not shown in this figure).

The main consequences of using strategy A.1 are: (i) inlet air must be heated up to high temperature $\left(\geqslant 750{ }^{\circ} \mathrm{C}\right)$ in order to have 

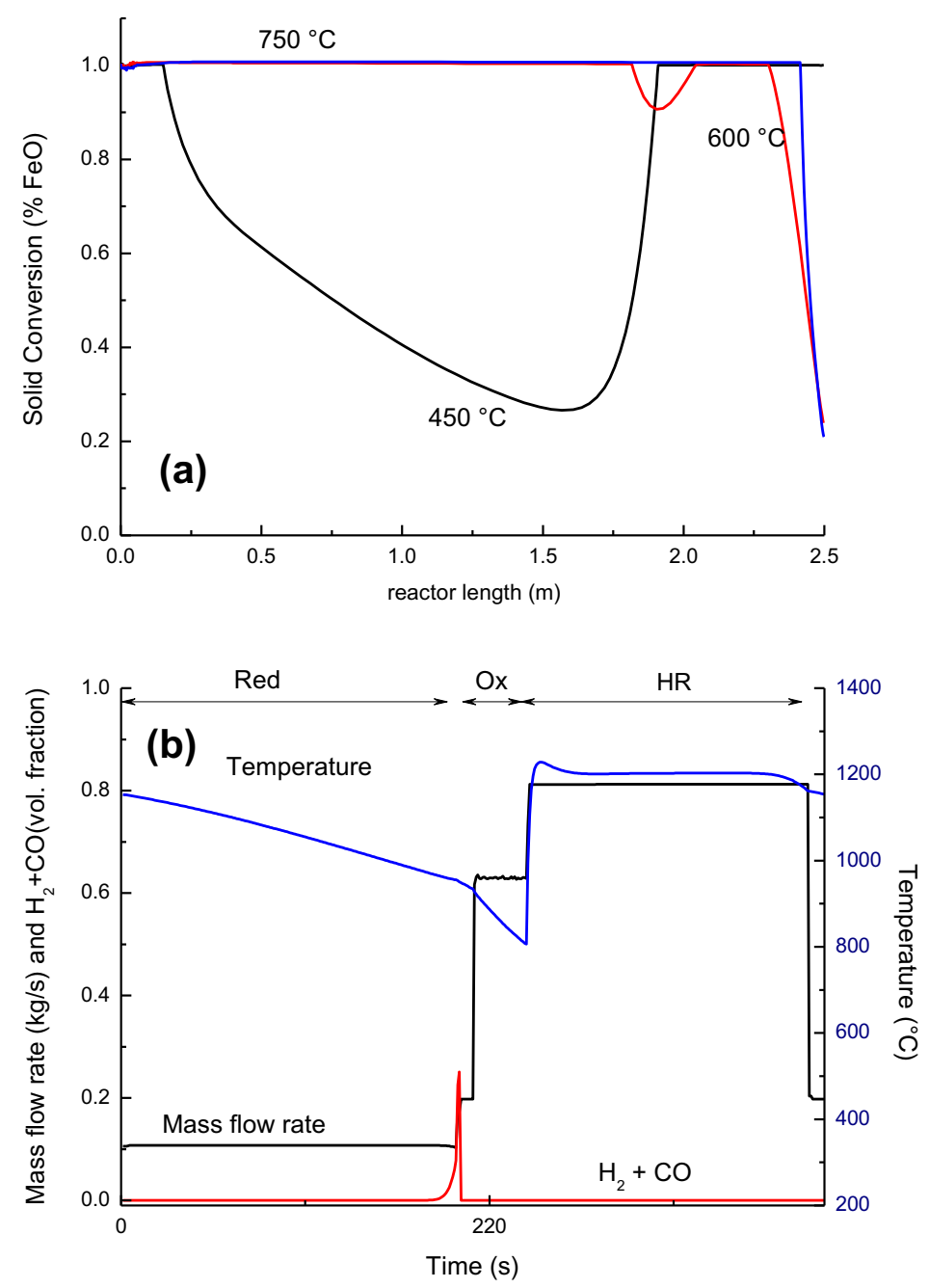

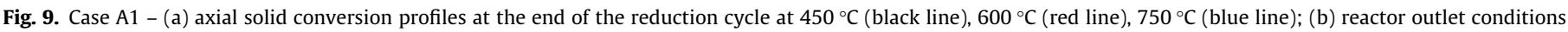

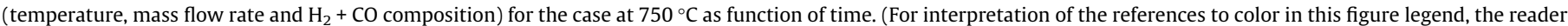
is referred to the web version of this article.)

an average solid temperature high enough to keep the kinetics during the reduction cycle sufficiently fast; (ii) in presence of syngas with high CO content, fuel slip occurs when the solid reduction is not properly accomplished; (iii) the solid conversion profile (with air at $450{ }^{\circ} \mathrm{C}$ and also at $600^{\circ} \mathrm{C}$ ) shows that the solid is not well converted in the center of the bed: this can be explained considering the temperature profile at the beginning of the reduction cycle and the different velocities of reaction and heat front. The fuel conversion will occur in the initial part where the solid particle are exposed to the fresh fuel, rich in $\mathrm{H}_{2}$ for a longer time- and in the hot (last) part of the reactor where the kinetics occurs fast for both $\mathrm{CO}$ and $\mathrm{H}_{2}$. (iv) the temperature profile at the reactor outlet is not uniform, when working at $450{ }^{\circ} \mathrm{C}$ and $600{ }^{\circ} \mathrm{C}$, because of the effect of the solid conversion: during the oxidation cycle the air is able to oxidize the total amount of wustite, but the final solid temperature strongly depends on the active weight content of the solid phase that has to be converted. The unconverted solid reduces the maximum temperature and, when the reaction front reaches the end of reactor, the solid temperature profile is not uniform along the bed (see Fig. 8), so the gas temperature at the reactor outlet cannot be constant (this is not true when the air is fed at $750{ }^{\circ} \mathrm{C}$ because the solid conversion is almost complete as showed in Fig. 9); (vi) the non-uniform temperature profile along the reactor leads to some hot spots that must be avoided to have the material in a safe operating conditions; (vii) since fuel conversion is not complete, $\mathrm{CO}_{2}$ does not have the required high purity for storage and some additional treatments would be needed.

For strategy A.2 the reactors have been operated with lower solid active weight content (10 wt.\%). The main consequences of this strategy are the shorter time cycle ( $88 \mathrm{~s}$ vs. $300 \mathrm{~s}$ ) and the possibility to have an average solid temperature higher than for strategy A.1, with air at $450^{\circ} \mathrm{C}$. On the other hand, the solid conversion is complete in almost the entire bed (except for the first part) even if air is fed at $450{ }^{\circ} \mathrm{C}$. This is because the solid temperature profile is not the same as in case A.1, since the cycle time during the oxidation is not long enough to cool down the entire bed (Fig. 10b). The amount of $\mathrm{H}_{2}$ is high enough to convert the solid in the cold part of the reactor while the $\mathrm{CO}$ is basically converted along the bed where the temperature is higher.

As it can be noted, the solid temperature changes from the reduction and the oxidation in a range of about $100^{\circ} \mathrm{C}$. This effect can be explained with the higher amount of solid inert material which increases the thermal inertia of the system. Once the solid oxidation occurs, the heat of reaction is transferred to the gas and solid phase in which the high amount of inert does not react. This temperature stability is a positive effect of this configuration because the solid material is not subjected to excessive thermal stresses. 

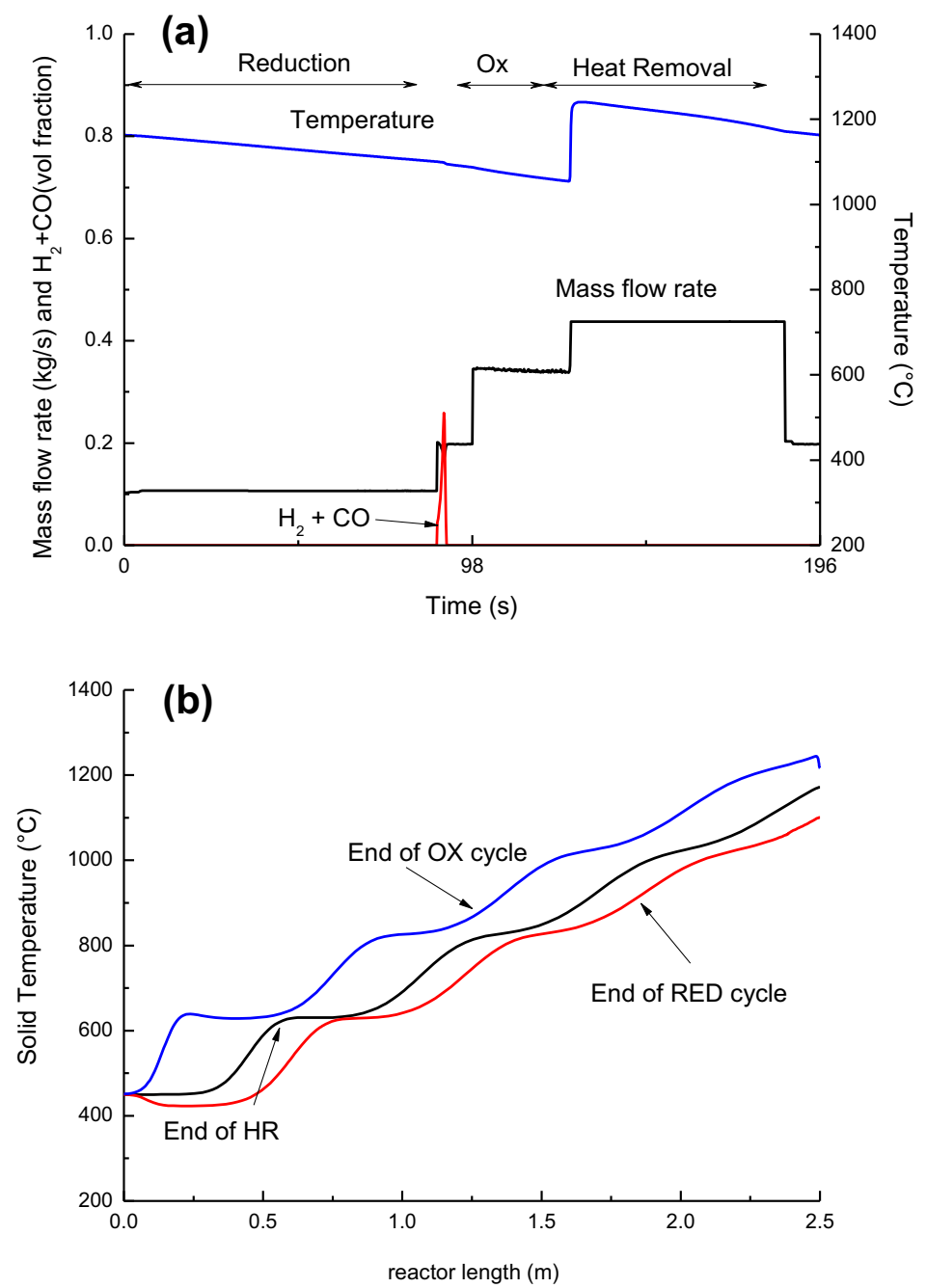

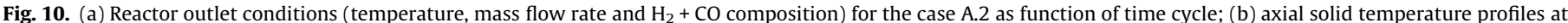

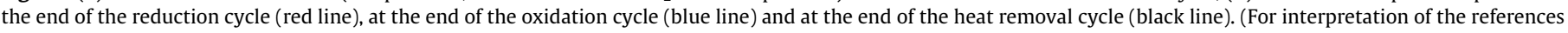
to color in this figure legend, the reader is referred to the web version of this article.)

On the contrary, the gas temperature profile at the reactor outlet is never constant even if the maximum $\Delta T$ for the reduction and the oxidation are respectively $40^{\circ} \mathrm{C}$ and $80^{\circ} \mathrm{C}$ (Fig. 10a): in a packed bed reactor the temperature at the outlet is close to the solid temperature at the end of the reactor, so it depends on the heat front velocity. The solid temperature profile is not constant along the reactor but, moving from the initial part to the final, the temperature increases. The main consequence of this behavior is that the power unit never receives a constant mass flow rate at constant temperature so the turbomachineries behavior is constantly under transient conditions in a relatively short time cycle. However, the temperature variation is quite limited (less than $50{ }^{\circ} \mathrm{C}$ ): the compatibility with the specifications imposed by power plant components has to be assessed.

The strategy A.3 has been also investigated in order to be able to feed the syngas in the hot part of the reactor (counter-current feeding). With this configuration the syngas will reacts with $\mathrm{Fe}_{2} \mathrm{O}_{3}$ since the solid temperature is high enough (above $1100^{\circ} \mathrm{C}$ ) ensuring fast kinetics also for the $\mathrm{CO}$ oxidation. The main problem of this configuration is related to the different velocities of the heat and reaction fronts as already pointed out in the description of the reactor model: with the mass flow rates that are listed in

Table 4 for the case of an air inlet temperature of $450{ }^{\circ} \mathrm{C}$ the reaction front is much faster than the heat front, so that the fresh syngas meets the cold part of reactor before the heat front preheats the unconverted solid. The risk of this configuration is that after few seconds the outlet gas from the reactor will be almost unconverted as for strategy A. 1 with air at $450{ }^{\circ} \mathrm{C}$. In order to fix this problem, the heat front must be as fast as the reaction front during the reduction cycle. Another problem that has been observed in the reactor behavior during the oxidation cycle is the possibility of hot spot formation: air is fed to the reactor when the heat front is not already at the end of the reactor, when the reaction front reach the hot part of the reactor the temperature increase is too high to assure solid material stability (higher than $1450{ }^{\circ} \mathrm{C}$ which is the melting point for the ilmenite).

As already discussed, $\tau_{r / h}$ is close to 1 when the amount of inert gases in the syngas is extremely high. With high inert content in the syngas stream the heat front velocity can be almost the same of the reaction front velocity, and strategy A. 3 could be used in a power plant. Adopting this solution means that high inert mass flow rate must be available in the plant: in a power plant with $\mathrm{CO}_{2}$ capture, it is possible to recirculate some $\mathrm{CO}_{2}$ (or add some steam with increased efficiency penalty).

Increasing the mass flow rate with inert gas has two main effects: the reaction rate during the reduction cycle is slower because the gas concentration is lower and the gas velocity is higher resulting increased the pressure drop over the reactor and, as conse- 
quence, $\mathrm{CO}_{2}$ compression energy requirements are higher. If the same configuration is adopted with a lower solid active weight content (as for the case A.2) the problem still exists. This configuration does not seem to have advantages over strategy A1 and the results are not presented and further discussed in this paper.

As was already pointed out, the main problem of using ilmenite as oxygen carrier in a packed bed reactor for CLC is the slow reaction kinetics of the solid reduction with $\mathrm{CO}$. The effect of the WGS reaction has been investigated for strategy A.4. The possibility of using syngas from an external WGS process has not been considered in this study, because WGS reaction in IGCC with $\mathrm{CO}_{2}$ capture, which is used to obtain $\mathrm{CO}_{2}$ that is ready to be separated in a physical absorption process (i.e. Selexol ${ }^{\text {}}$ process), leads to a high efficiency penalty due to steam extraction for the WGS reaction from the steam cycle and loss of calorific value at mid-low temperature.

When the WGS reaction occurs directly with the CLC reactions the effect is different because the $\mathrm{H}_{2} \mathrm{O}$ is already present in the syn-

(a)
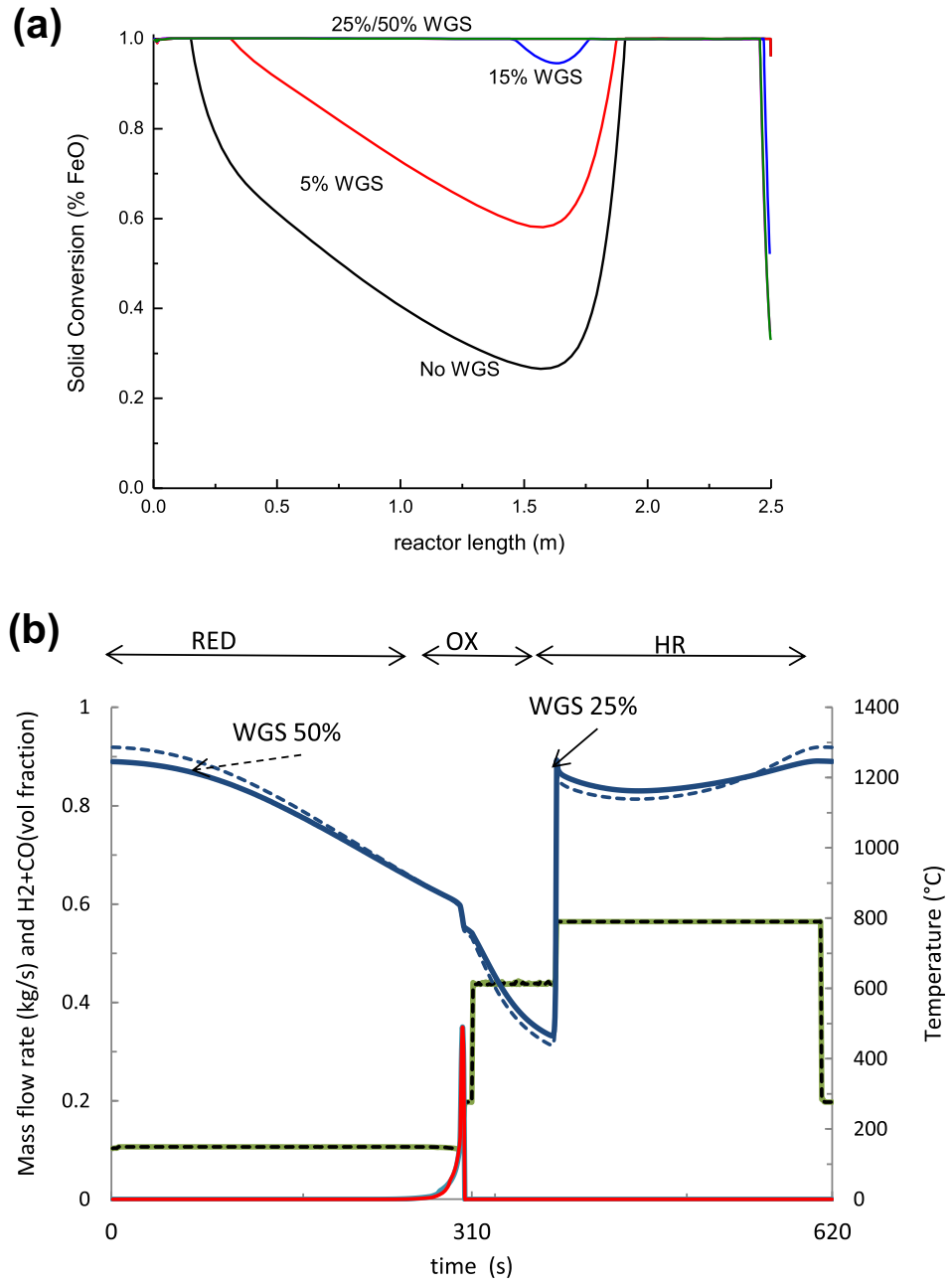

(c)

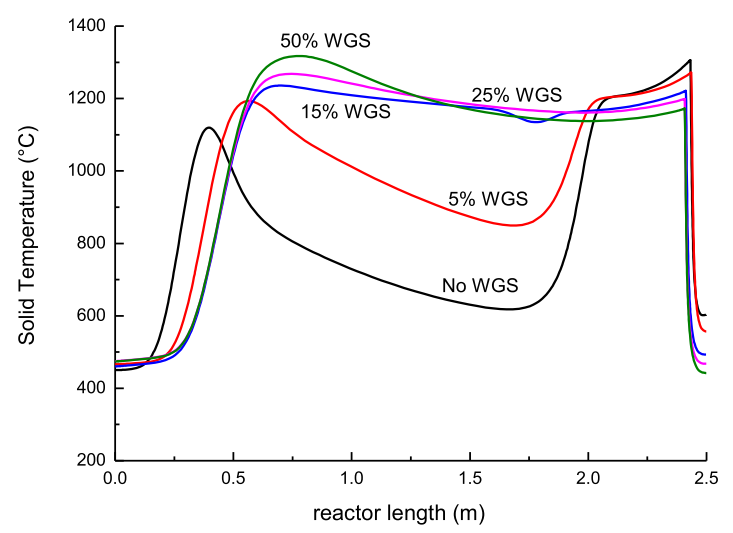

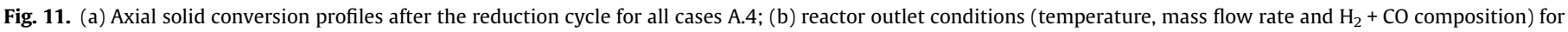
the case A.4 -50\% WGS as function of time cycle; (c) axial solid temperature profile for all cases A.4 at the end of oxidation cycle. 
gas stream due to the $\mathrm{H}_{2}$ oxidation during the reduction cycle and heat of reaction is released at high temperature. The WGS reaction is slightly exothermic and is favored at low temperatures. The combined effect of WGS and $\mathrm{H}_{2}$ oxidation helps the syngas conversion because the $\mathrm{CO}$ oxidation can occur at low temperature and solid conversion is almost complete. Since no reaction rates have been measured for the WGS, the results presented below are based on a sensitivity analysis using the chemical equilibrium conversion.

Increasing the $\mathrm{CO}$ conversion through the WGS reaction the $\mathrm{H}_{2}$ production during the CLC process permits to convert almost completely $\mathrm{Fe}_{2} \mathrm{O}_{3}$ to $\mathrm{FeO}$ (Fig. 11a). The present strategy appears very promising, and the application is based on the assumption to use a solid material with catalytic activity for WGS, which is stable if subjected to repetitive cycles under high temperature and able to obtain a high reaction rate also at low temperatures (where kinetics is slower, but the equilibrium conversion is higher).

When the CO conversion by the WGS reaction is $25 \%$ or $50 \%$ of the chemical equilibrium, the solid conversion is almost complete (Fig. 11a), the air mass flow rate and the temperature at the reactor outlet during the heat removal cycle are useful for a Gas Turbine (Fig. 11b). It should be noted that the temperature is not constant as in case A. 1 using air at $750{ }^{\circ} \mathrm{C}$ because of heat of reaction of the WGS reaction. The effect of WGS changes the distribution of the heat of reaction: in the first part of the reactor the WGS reaction changes the temperature profile (Fig. 11c). When comparing the cases A4 - 25\% and A4 - 50\%, it is possible to notice that when WGS is more active, the solid temperature profile at the end of the oxidation cycle is not constant and the gas temperature at the reactor outlet changes from $1300^{\circ} \mathrm{C}$ to $1200^{\circ} \mathrm{C}$, affecting the GT behavior.

In conclusion, if the solid material (ilmenite) is able to catalyze the WGS reaction by converting some $\mathrm{CO}$ to $\mathrm{H}_{2}$, especially in first part of reactor, this configuration can be suitable for packed bed reactor integration in a CLC power plant. Otherwise, some WGS catalyst (that should be able to withstand high temperatures) can be added to the ilmenite to give some activity towards WGS.

\subsection{Strategy B: reduction/heat removal/oxidation/purge}

In strategies $B$ the heat removal phase is performed after the reduction phase. For cycle strategies $B$ the reactor is switched to the reduction cycle when the reaction front - during the oxidation - reaches the end of reactor and the heat front is still in the first part of the reactor. In this case the bed temperature is close to $1200{ }^{\circ} \mathrm{C}$ so the kinetics is favored except for the first part where the reaction occurs at $450^{\circ} \mathrm{C}$.

For case B.1 and B.2 the axial solid temperature and solid conversion profiles at the beginning of each cycle (reduction, heat removal and oxidation) are shown in the Figs. 12a and b respectively. The gas stream conditions (temperature, mass flow rate and fuel species) are showed in Fig. 13 at the reactor outlet. It is worth noting that the temperature is almost constant during the reduction and heat removal cycle for strategy B.1.

Cycle strategy B.1 is suitable for the integration of packed bed reactors in a power plant. The reduction reaction is slightly endothermic and the maximum bed temperature only slightly decreases during the heat removal cycle (about $10^{\circ} \mathrm{C}$ ), so that the inert gas stream is produced at constant high temperature and high pressure. This effect depends on the fuel gas composition and on the oxygen carrier properties: if the syngas is richer in $\mathrm{H}_{2}$ the reduction reaction with ilmenite becomes more endothermic and the maximum solid temperature decreases; in this last case the efficiency of the system is lower since the gas turbine is fed with a stream with lower gas temperature. The $\mathrm{H}_{2}$ and $\mathrm{CO}$ slip does not occur during the cycle except for the purge cycle (see Fig. 14)
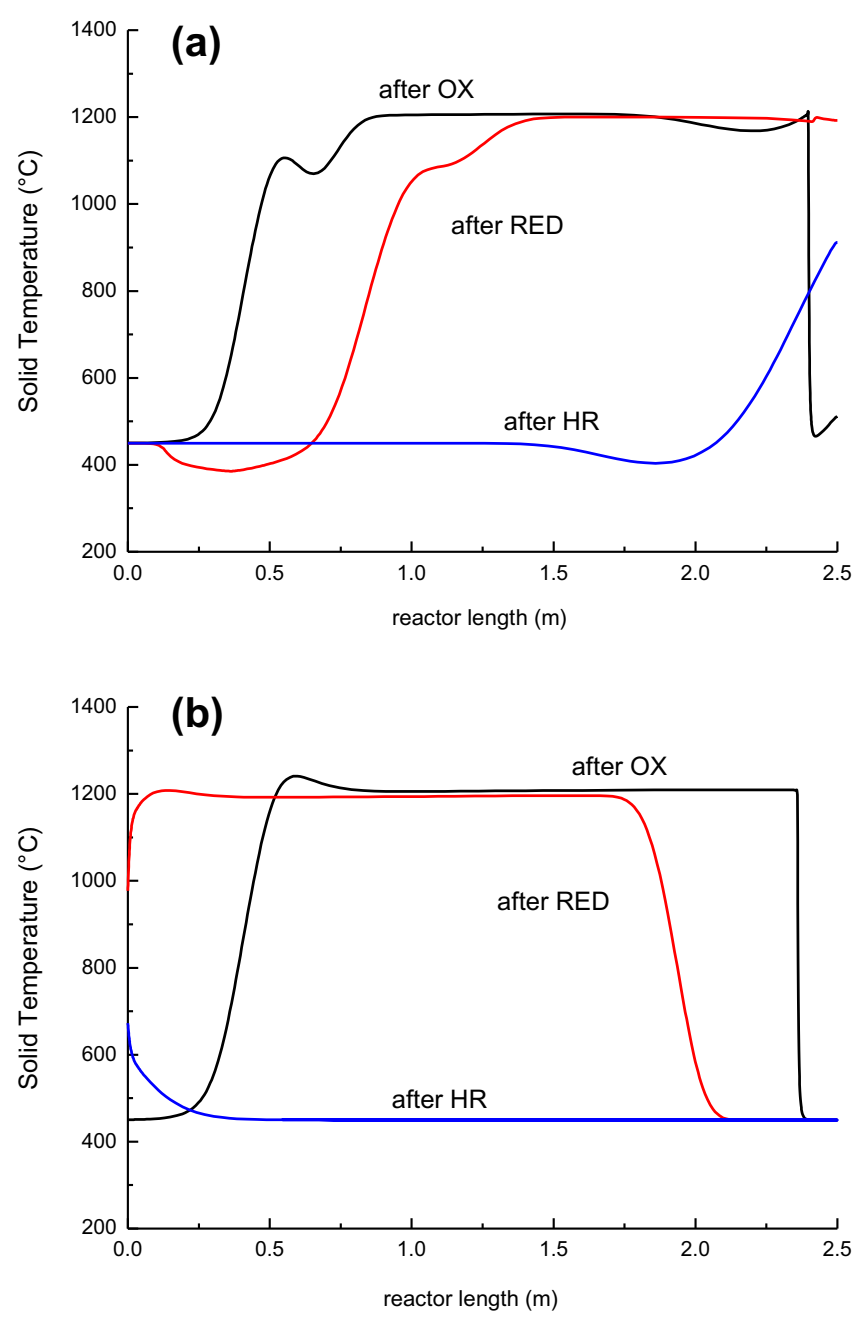

Fig. 12. Axial solid temperature profiles at the end of the reduction cycle (red line), at the end of oxidation cycle (black line) and at the end of Heat Removal cycle (blue line) for case B.1 (a) and B.2 (b); for case B.1 the gasses are fed from the left side for case B.2 air is fed from the left side while $\mathrm{N}_{2}$ and syngas are fed from the right side. (For interpretation of the references to color in this figure legend, the reader is referred to the web version of this article.)

Case B. 2 shows similar results. The reactor outlet gas temperature is constant during the heat removal cycle and the pure oxidation, but changes in the reduction cycle. In fact, a higher nitrogen mass flow rate is required during the heat removal cycle (+27\% respect to case B.1). The differences in gas stream temperature profile at the outlet of the reactor can be explained by considering the solid temperature profiles at the beginning of the related cycle (Fig. 12a vs Fig. 12b): for the reduction cycle, in case B.1 the gas temperature at the reactor outlet is the consequence of the heat front that moves (from left to right) from the position at the end of oxidation cycle (blue line) to the position at the end of reduction cycle (red line); in case B.2 the same behavior can be observed, but the heat front moves backward (from right to left) since the syngas is fed counter-currently. The same consideration is applicable for the different temperature profile of gases exiting the reactor during the oxidation cycle.

For the case B.2 the solid is completely converted during the reduction cycle because of the effect of reverse syngas feeding that allows to the syngas to meet the bed when the solid is at maximum temperature along the bed.

The difference in velocities of the heat and reaction front does not pose a problem for this configuration, as was discussed previ- 

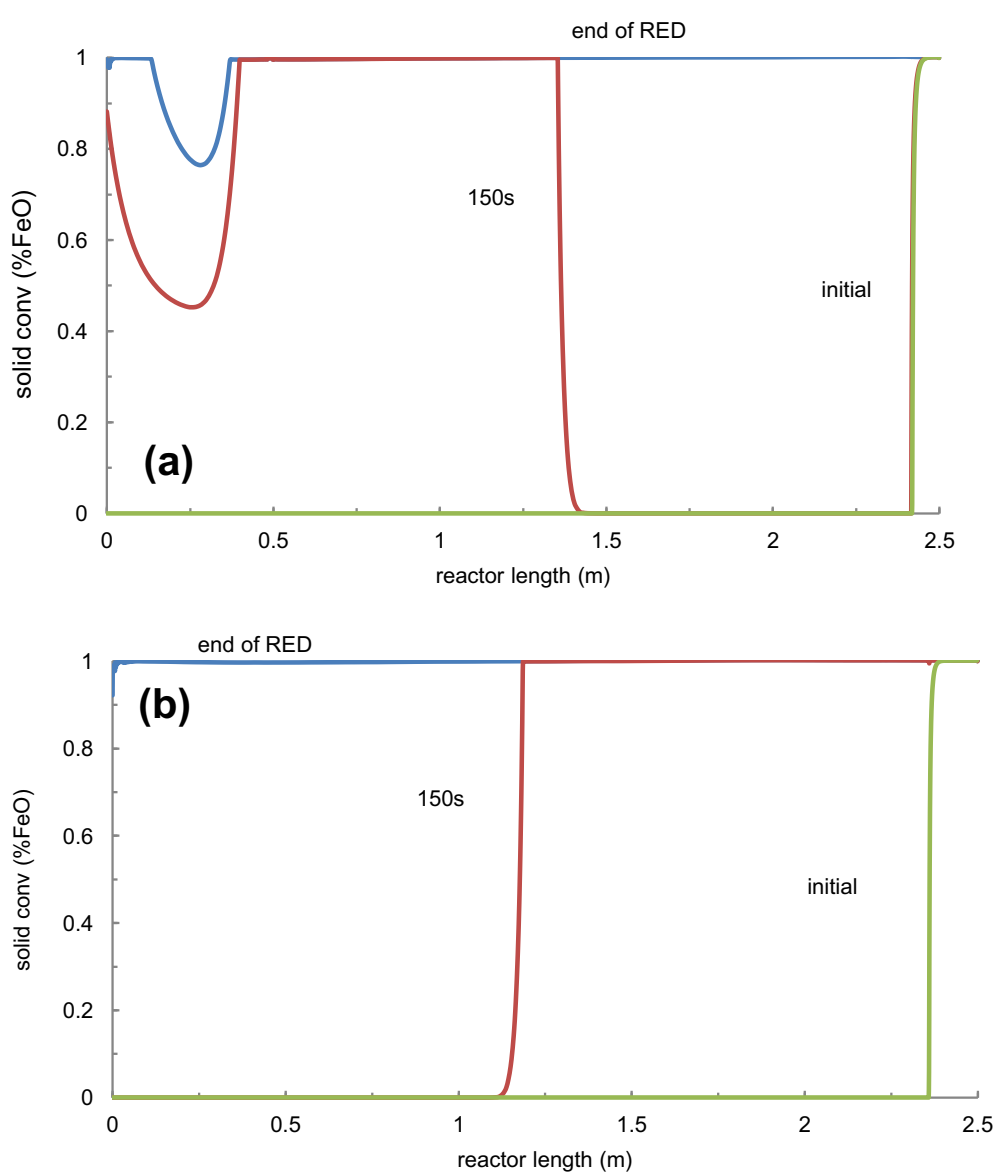

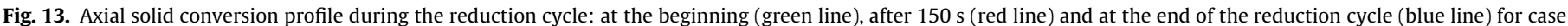

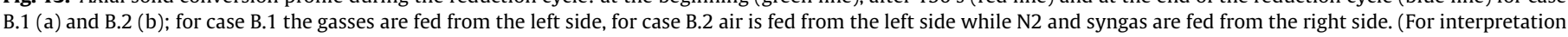
of the references to color in this figure legend, the reader is referred to the web version of this article.)

ously for case A.3: when the solid reduction is completed the heat produced during the oxidation is still stored in the bed and it can be used for the next cycle.

\subsubsection{Effect of $\mathrm{CO}$ oxidation reaction rate}

For the last cycle strategy B.2 a sensitivity analysis has been carried for the $\mathrm{CO}$ oxidation reaction rate. The reaction rate has been evaluated respectively at $5 \%-10 \%-20 \%$ of the base case to account the possibility of a slower kinetics for the reaction of $\mathrm{CO}$ with ilmenite, which is the most critical reaction and with the largest uncertainties: this decrease in the reaction rate corresponds to an activation energy $\left(E_{a}\right)$ of $96-103-110 \mathrm{~kJ} / \mathrm{mol}$ instead of $80 \mathrm{~kJ} /$ mol at $1200^{\circ} \mathrm{C}$. The $\mathrm{H}_{2}$ reaction rate has not been modified.

The results show that this strategy becomes infeasible if the reaction rate is $5 \%$ of the reaction rate of the base case. In this case the lowest kinetics does not allow converting the solid completely in the left side of the reactor and the gas at the reactor outlet cannot be directly used in a gas turbine.

When the reaction rate is $10 \%$ or $20 \%$ the effect of a slower kinetics does not affect the heat management of the system significantly. The $\mathrm{CO}$ is converted along the bed and the solid conversion does not drastically change the result already discussed for the base case. As a matter of fact, strategy B.2 is able to work with an oxygen carrier that is not very reactive (thus also when the ilmenite would be somewhat deactivated after a large number of cycles). The possibility to carry out the reduction cycle with the bed at high temperatures makes this strategy very efficient and suitable in terms of operability and integration in a power plant. As discussed in Fig. 4, at $1200{ }^{\circ} \mathrm{C}$ the chemical equilibrium for solid species shows the presence of metallic iron. For these strategies (B.1 and B.2) this condition must be verified, since kinetics at this temperature are faster and some Fe could be present.

\subsubsection{Effect of pressure drop}

For strategy B.2 an additional analysis has been carried out to account for the effect of the pressure drop that strongly affects power plant performance. The maximum pressure drops for strategy B.2 are $9.2 \%$ during the heat removal cycle that represents a consistent power loss for GT in a power plant. In addition, the reactor length is $2.5 \mathrm{~m}$ and diameter $0.3 \mathrm{~m}$ but in a large scale power plant, the reactor are expected to be bigger to reduce the number of reactors operating in parallel and the switching operations, so the pressure drop is expected to be higher (when using particle of the same size). For the reduction cycle (B.2) the maximum pressure drop is $0.5 \%$. In order to reduce the maximum pressure drop strategy B.2 has been considered with different cycle times, with an average superficial gas velocity equal for the different cycles keeping the reduction cycle constant. The reactor outlet gas condition is presented in Fig. 15. In this case the heat management is not affected by the different cycle time, so that the solid conversion and hot gas production occur properly according to the previous investigation. Maximum pressure drop is now $1.4 \%$ and some slight difference is detected in the transient behavior: lowering the mass flow rate the heat dispersion (especially during the heat removal cycle) becomes less significant so the transient step can be manipulated. The main problem of this configuration is related to the process economics. This strategy can be performed in a large scale power plant if a large number of reactors are present in order 

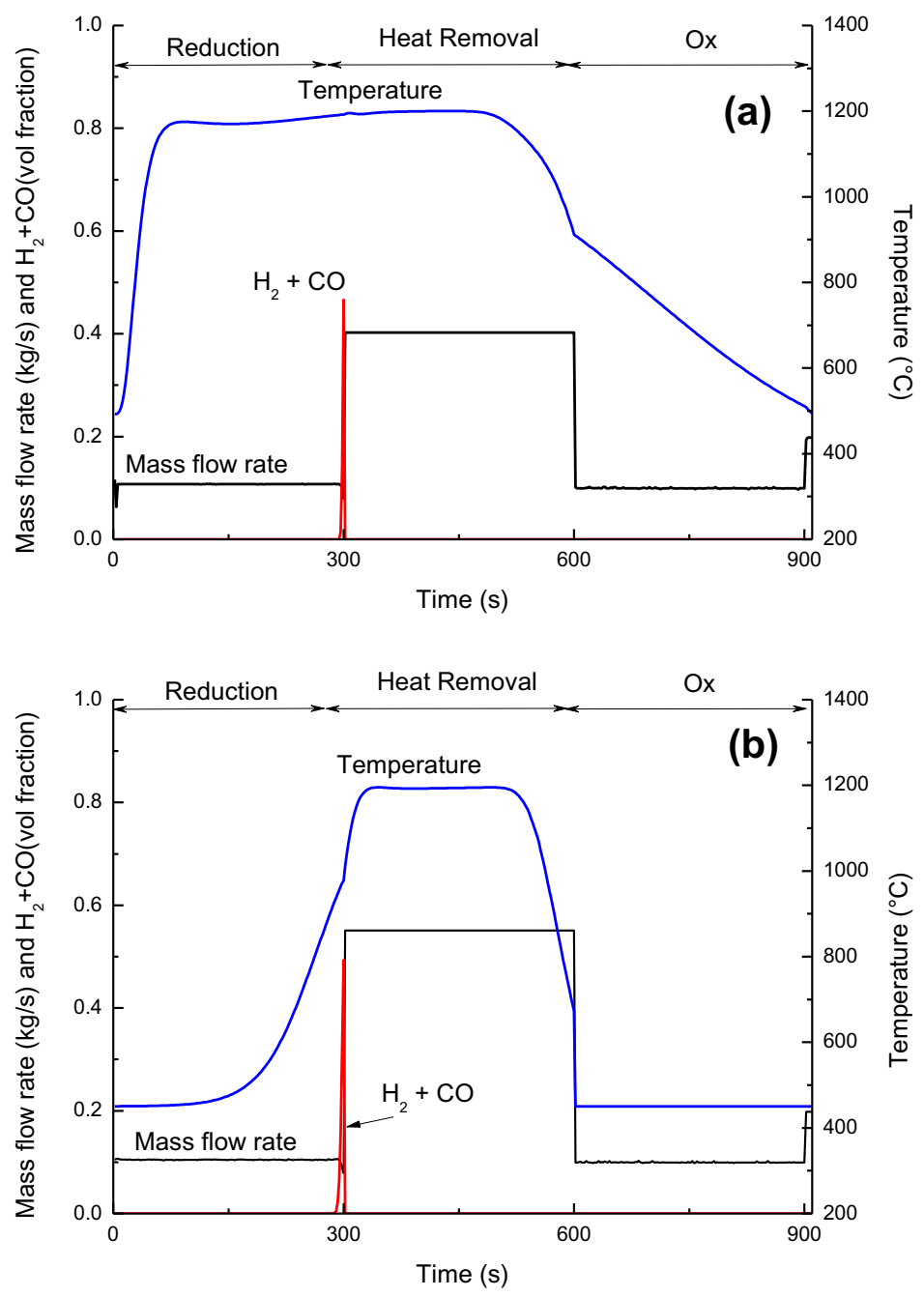

Fig. 14. Reactor outlet gas condition during the entire cycle for case B.1 (a) and B.2 (b).

achieve the required power production (hundreds of $\mathrm{MW}_{\mathrm{el}}$ ). The economic analysis and the effect on the overall power plant efficiency is not quantified here, but only discussed from a qualitative point of view.

\subsection{Effect of syngas composition}

A supplementary analysis has been carried out by changing the syngas composition, to investigate its effect on the axial solid temperature and solid conversion profiles with a $\mathrm{CO}_{2}$-rich syngas (gas composition $\mathrm{CO} 36.5 \%, \mathrm{H}_{2} 13.2 \%, \mathrm{~N}_{2} 1.3 \%, \mathrm{CO}_{2} 30 \%, \mathrm{H}_{2} \mathrm{O} 20 \%$ ), more similar to the expected composition of a coal syngas used in a power plant with $\mathrm{CO}_{2}$ capture, where $\mathrm{CO}_{2}$ should be used instead of $\mathrm{N}_{2}$ as transport gas in lock hoppers. The syngas mass flow rate was changed $(0.102 \mathrm{~kg} / \mathrm{s})$ in order to keep the same fuel thermal input (500 kW based on syngas LHV).

This analysis has included the most promising strategies according to the previous comparison: A.2, A.4 (with a WGS activity equal to $25 \%$ and $50 \%$ of the conversion at equilibrium), B. 1 and B.2.

For strategies A.2, B.1 and B.2 the axial solid conversion and the solid temperature profiles are not affected according to the kinetic model already described: the rate of conversion is the same and the reaction enthalpy does not change the temperature profile. For the strategy A.4 the different gas composition changes the solid conversion and therefore the temperature and gas conditions at the reactor outlet. WGS activity reduces the solid conversion in for strategy A4 - 25\% (not for the strategy A4 - 50\%) if compared with the base case syngas composition. Another effect is a different gas temperature at the reactor outlet for case $\mathrm{A} 4-50 \%$ : with $\mathrm{CO}_{2}-$ rich syngas the WGS activity is less pronounced (less $\mathrm{H}_{2} \mathrm{O}$ and higher $\mathrm{CO}_{2}$ ) so the heat of reaction does not change the axial solid temperature profile at the end of reduction cycle as was observed before. The main effect is that the gas temperature at the reactor outlet during the heat removal cycle presents smaller variations (close to $100^{\circ} \mathrm{C}$, instead of $150{ }^{\circ} \mathrm{C}$ for the base case).

\subsection{Comparison of strategies}

In order to summarize the results three different coefficients have been defined:

- Fuel conversion efficiency: this quantifies the amount of syngas that is leaving the reactor not oxidized. This parameter is in terms of energy loss as the amount of fuel Low Heat Value not converted during the reduction cycle.

$\varepsilon_{\text {conv }}=1-\frac{\int_{\text {tred }=0 \mathrm{~s}}^{\text {tred }=\text { end }}\left(\dot{m}_{H 2}^{\text {out }} \cdot L H V_{H 2}+\dot{m}_{C O}^{\text {out }} \cdot L H V_{C O}\right) d t}{\dot{m}_{\text {syngas }}^{\text {in }} \cdot L H V_{\text {syngas }}^{\text {in }} \Delta t_{\text {red cycle }}}$ 


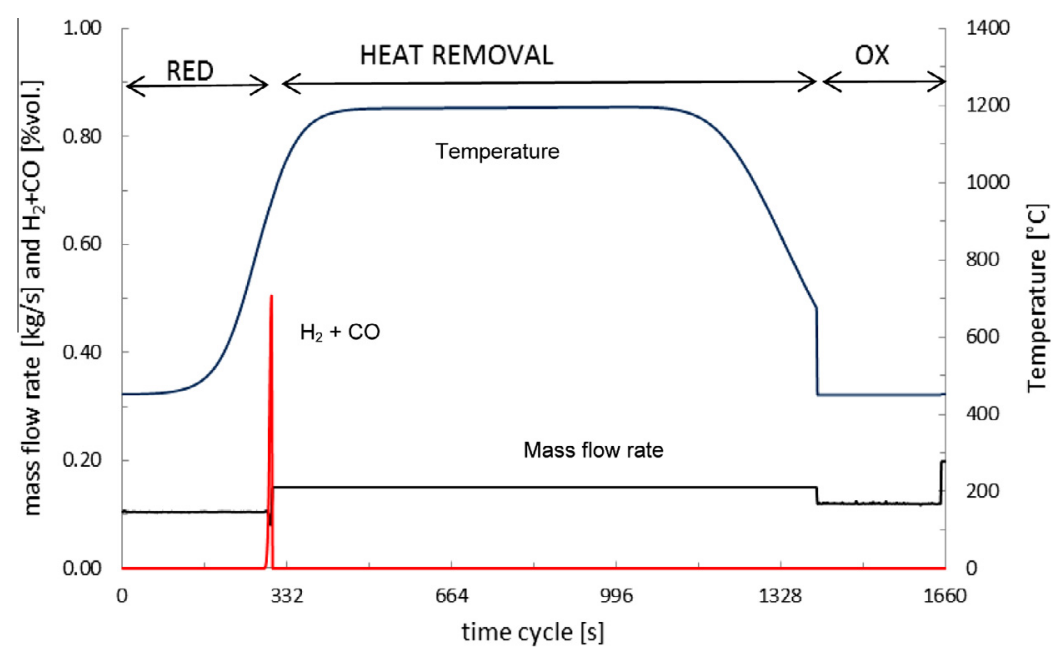

Fig. 15. Reactor outlet gas condition during the entire cycle for case B.2: reduction ( $300 \mathrm{~s})$, heat removal (1100 s) and oxidation ( $250 \mathrm{~s}$ ).

- High temperature production time: it represents the percentage of time $t_{\text {HTgas }}$ - with respect to the total cycle $t_{\text {cycle }}$ - respectively oxidation heat removal cycle for Strategies A and heat removal cycle for Strategies B - in which the mass flow rate (air or $\mathrm{N}_{2}$ ) at the reactor outlet is continuously (virtually) constant and his temperature is in the range of $1150-1250^{\circ} \mathrm{C}$. This coefficient represents an estimation of the time to have a gas stream useful for electricity production in the gas turbine. The relative standard deviation is also computed to highlight the instantaneous change of enthalpy during the high temperature production time.

$\tau_{H T_{\text {gas }}}=\frac{t_{H T_{\text {gas }}}}{t_{\text {cycle }}}$

- High temperature energy efficiency of the system: this coefficient represents how much energy stored in the fuel (here simply considered as the LHV of the inlet syngas) is converted in a high temperature gas stream for the GT. The remaining heat is

Table 5

Summary of performances of the various cycle strategies considered.

\begin{tabular}{|c|c|c|c|c|}
\hline & $\varepsilon_{\text {conv }}(\%)$ & $\tau_{\text {HTgas }}(\%$ std. dev.) & $(\%)$ & $\eta_{H T}(\%)$ \\
\hline \multicolumn{5}{|c|}{ Syngas base composition } \\
\hline A1 450 & 62.6 & 11.7 & 2.2 & 13.1 \\
\hline A1 600 & 99.9 & 75.6 & 0.7 & 72.7 \\
\hline A1 750 & 98.7 & 83.0 & 0.9 & 72.0 \\
\hline $\mathrm{A} 2$ & 98.5 & 68.6 & 1.8 & 62.7 \\
\hline A4 (5 wgs) & 85.0 & 16.7 & 2.0 & 18.7 \\
\hline A4 (15 wgs) & 98.0 & 71.3 & 2.2 & 77.6 \\
\hline A4 (25 wgs) & 98.3 & 76.0 & 2.5 & 83.4 \\
\hline A4 (50 wgs) & 98.3 & 40.0 & 2.6 & 43.4 \\
\hline B1 & 99.1 & 76.0 & 1.0 & 62.1 \\
\hline B2 & 98.5 & 73.3 & 0.7 & 81.7 \\
\hline \multicolumn{5}{|c|}{ Sensitivity analysis on $\mathrm{CO}$ reduction reaction rate } \\
\hline $\mathrm{B} 2(\operatorname{rr} 5)$ & 87.7 & 55.3 & 0.9 & 61.5 \\
\hline $\mathrm{B} 2(\mathrm{rr} 10)$ & 97.1 & 69.3 & 0.9 & 77.2 \\
\hline B2 (rr20) & 99.2 & 73.3 & 0.8 & 81.8 \\
\hline \multicolumn{5}{|c|}{ Cycle with different time } \\
\hline $\mathrm{B} 2\left({ }^{\mathrm{a}}\right)$ & 97.7 & 73.5 & 0.8 & 82.0 \\
\hline \multicolumn{5}{|c|}{$\mathrm{CO}_{2}$-rich syngas composition } \\
\hline A2 & 99.9 & 68.0 & 1.8 & 60.9 \\
\hline A4 25 & 97.6 & 60.7 & 1.3 & 65.9 \\
\hline A4 50 & 97.8 & 72.3 & 2.0 & 78.5 \\
\hline B1 & 100.0 & 72.7 & 1.0 & 58.4 \\
\hline B2 & 100.0 & 74.0 & 0.9 & 81.0 \\
\hline
\end{tabular}

\footnotetext{
a Maximum pressure drops are $1.4 \%$ instead of $9.2 \%$ of B.2 base case.
}

sent to produce HP steam for steam cycle or the unconverted fuel because of fuel slip, since the present analysis has been carried out assuming no heat losses through the reactor walls.

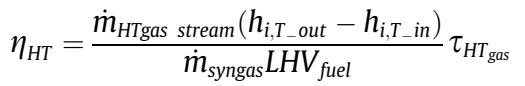

where $\dot{m}_{\text {HTgasstream }}$ is the amount of constant mass flow rate during the oxidation cycle (or Heat Removal cycle for case B.1 and B.2), $h_{i, T-o u t}$ is the average gas enthalpy of the gas stream at the reactor outlet in the selected range of temperatures in which the hot gas stream is produced, $h_{i, T i n}$ is the enthalpy at the reactor inlet condition and $\tau_{\text {HTgas }}$ is the relative high temperature production time as previously defined.

Table 5 summarizes the performance coefficients for the various cases discussed before. The fuel conversion is always higher than 97\% except for case at A.1 and A.4 with low WGS activity (5\%) and for the case B.2 with the lower reaction rate. The high temperature production time is always higher than $70 \%$ for the configuration with a proper solid conversion during the reduction that have been considered as promising for the integration in a power plant and also for the configuration A. 1 with air at $600^{\circ} \mathrm{C}$ and $750{ }^{\circ} \mathrm{C}$. When $\tau_{H T_{g a s}}$ is lower than $70 \%$ the solid conversion is not complete during the reduction cycle or the solid temperature profile is homogeneous (i.e. A4 - 50\%).

The effect of the mass flow rate is also well represented when comparing the strategies B.1 and B.2: the increase in the mass flow rate for case B.2 is more important than the lower time at high temperature so the resulting $\eta_{H T}$ is finally somewhat higher for case B.2.

The sensitivity analysis on the $\mathrm{CO}$ reaction rate shows that if the kinetics is slower (20\% of the base case) the same efficiency $\eta_{\mathrm{HT}}$ can be reached and this confirms the feasibility of this configuration even with an oxygen carrier with a lower reactivity. The comparison between the base syngas and syngas with the new syngas composition confirms the considerations already reported in the results discussion.

For a fixed maximum solid temperature, the systems that are operated under limited temperature gradient are expected to generate less entropy in the CLC process (with increased 2nd law efficiency). However, as in the direct combustion process, the minimum exergy losses are obtained when the chemical energy of the fuel is converted into thermal power at very high temperature (ideally infinite) and thus, for the CLC system, the main limit is the maximum solid temperature that limits the maximum gas temperature. 
Furthermore, in the perspective of arranging a power plant based on a CLC loop process, the 2nd law efficiency of the overall power plant is much more relevant than efficiency of the single CLC loop process.

Along with exergy destruction inside the CLC, also the irreversibilities related to energy recovery from the CLC loop exhaust streams should be accounted for. In the present manuscript the 2nd law efficiency of the plant is not defined and discussed. From a qualitative point of view, it is possible to conclude the highest efficiency is expected when the CLC loop behaves like a combustor of a gas turbine based combined cycle (as HR and OX reactors in Fig. 1).

In this case the fuel energy is introduced at high temperature (the typical value tolerated by a gas turbine engine, $\sim 1200{ }^{\circ} \mathrm{C}$ ) in the thermodynamic cycle. This allows to convert heat to power with the highest efficiency (Fig. 2). Heat released during the reduction phase is sent to the steam cycle (operating at $\sim 600^{\circ} \mathrm{C}$ ) and converted to power with lower efficiency.

\section{Conclusions}

Different cycle strategies for the heat management in a packed bed reactor for chemical looping combustion have been simulated with a numerical model and discussed in detail in the present work. Different layouts have been compared in order to discuss the effect on the axial solid temperature and solid conversion profiles, the fuel conversion and the reactor outlet conditions. The effect of WGS activity of the oxygen carrier has been also commented. A sensitivity analysis has been performed for strategy B.2 to verify the feasibility of the process with a lower reaction rate. Furthermore, the performance of the reactor with a different syngas composition has been also investigated for the best cycle strategies.

Three different coefficients have been calculated to enable the comparison between the different strategies and to quantify the potential of the packed bed reactor for CLC technology. For case A4 - 25\% the high temperature efficiency reaches $83.4 \%$ which is the best performance (with high standard deviation) followed by the strategy B.2 (81.7\% with significantly low standard deviation). The difference is mainly accounted for the different time at high temperature (respectively 228 s for A.4 - 25\% and 220s for B.2)

In a pressurized fluidized bed reactor system (PFBR) for CLC operation the high temperature efficiency can reach typically $75-$ $85 \%$ which is close to the best cases here discussed. However, the PFBR technology has to overcome some technical challenges in terms of solid circulation at elevated pressures, so that packed bed reactor technology represents a very interesting alternative for the short mid-term.

From a technical point of view, all the systems here discussed need high temperature valves (at least $1200^{\circ} \mathrm{C}$ ) which represents a critical component in the design. Another issue is the number of reactors operating in parallel to reduce the pressure drop and have continuous operation, which would affect the investment cost of the power plant.

For case B.1 and B.2 a high amount of pure nitrogen is required for the heat removal cycle. Usually the IGCC with $\mathrm{O}_{2}$ blown gasifier has some $\mathrm{N}_{2}$ from ASU but in this case the amount of $\mathrm{N}_{2}$ is extremely high (from 6 to 7 times the amount of wet syngas) so the possible solution is to use a semi-closed cycle where $\mathrm{N}_{2}$ is recirculated at HRSG outlet to the compressor inlet: in this case the operating fluid for the GT is not air but pure nitrogen so the turbomachineries have to be tested, even if the small differences between air and nitrogen do not pose difficult challenges for the GT design. In terms of plant management, the system is dynamically operated and the lower the cycle time the higher the number of flow switches rendering the system more complex.

The present work has shown the potentials of packed bed reactor technology to work at pressurized conditions for $\mathrm{CO}_{2}$ capture from a coal-based power plant. The possibility to produce a hot gas stream at high pressure at almost constant operating conditions makes this technology feasible to be coupled with an efficient thermodynamic cycle. The main issues of the integration of PBR for CLC in a large scale power plant, operating with the most efficient strategies here discussed, with a performance analysis (i.e. electrical efficiency, $\mathrm{CO}_{2}$ capture ratio, etc... .) and with a prediction of the most relevant effects on the plant thermal balance and on its main components, will be discussed in a future work.

\section{Acknowledgement}

The research leading to these results has received funding from the European Union Seventh Framework Programme (FP7/20072013) under Grant Agreement No. 268112 (Project acronym DEMOCLOCK).

\section{References}

[1] IPCC, IPCC Special Report on Carbon Dioxide Capture and Storage. Prepared by Working Group III of the intergovernmental Panel on Climate Change [Metz, B., O. Davidson, H. C. de Coninck, M. Loos, and L. A. Meyer (eds.)]. Cambridge University Press, Cambridge, United Kingdom and New York, NY, USA, 2005.

[2] The Future of Coal - An interdisciplinary MIT study, Massachusetts Institute of Technology, 2007, ISBN:978-0-615-14092-6, <http://web.mit.edu/coal/ The_Future_of_Coal.pdf $>$.

[3] DOE/NETL Carbon Dioxide Capture and Storage RD\&D Roadmap, NETL, 2010, <http://www.netl.doe.gov/technologies/carbon_seq/refshelf/ CCSRoadmap.pdf $>$.

[4] J. Adanez, A. Abad, F. Garcia-Labiano, P. Gayan, L.F. De Diego, Prog. Eng. Comb. Sci. 38 (2) (2012) 215-282.

[5] D. Sridhar, A. Tong, H. Kim, L. Zeng, F. Li, L.-S. Fan, Eng. Fuels 26 (4) (2012) 2292-2302.

[6] S. Rifflart, A. Hoteit, M.M. Yazdanpanah, W. Pelletant, K. Surla, Eng. Proc. 4 (2011) 333-340.

[7] T. Pröll, J. Bolhàr-Nordenkampf, P. Kolbitsch, H. Hofbauer, Fuel 89 (6) (2010) 1249-1256.

[8] C. Linderholm, T. Mattisson, A. Lyngfelt, Fuel 88 (11) (2009) 2083-2096.

[9] M. Ishida, H. Jin, Chemical Looping Combustion power generation plant, system. US5447024, 1995.

[10] S. Consonni, G. Lozza, G. Pelliccia, G.S. Rossini, F. Saviano, J. Eng. Gas. Turb. Power 128 (2006) 525-534.

[11] S. Noorman, F. Gallucci, M. van Sint Annaland, J.A.M. Kuipers, Chem. Eng. J. 167 (1) (2011) 369-376.

[12] P. Gayán, I. Adánez-Rubio, A. Abad, L.F. De Diego, F. García-Labiano, J. Adánez, Fuel 96 (2012) 226-238

[13] C. Dueso, M. Ortiz, A. Abad, F. García-Labiano, L.F. De Diego, P. Gayán, J. Adánez Chem. Eng. J. 188 (2012) 142-154.

[14] T.A. Brown, F. Scala, S.A. Scott, J.S. Dennis, P. Salatino, Chem. Eng. Sci. 71 (2012) 449-467.

[15] T. Mattisson, E. Jerndal, C. Linderholm, A. Lyngfelt, Chem. Eng. Sci. 66 (20) (2011) 4636-4644.

[16] S. Noorman, F. Gallucci, M. van Sint Annaland, J.A.M. Kuipers, Ind. Eng. Chem. Res. 49 (20) (2010) 9720-9728.

[17] S. Noorman, F. Gallucci, M. van Sint Annaland, J.A.M. Kuipers, Ind. Eng. Chem. Res. 50 (4) (2011) 1968-1980.

[18] P. Moldenhauer, M. Rydén, A. Lyngfelt, Fuel 93 (2012) 351-363.

[19] A. Cuadrat, A. Abad, J. Adánez, L.F. De Diego, F. García-Labiano, P. Gayán, Fuel Proc. Technol. 94 (1) (2012) 101-112.

[20] M.M. Azis, E. Jerndal, H. Leion, T. Mattisson, A. Lyngfelt, Chem. Eng. Res. Des. 88 (2010) 1505-1514.

[21] J. Adanez, A. Cuadrat, A. Abad, P. Gayan, L.F.D. Diego, F. Garcia-Labiano, Eng. Fuels 24 (2010) 1402-1413.

[22] H. Leion, A. Lyngfelt, M. Johansson, E. Jerndal, T. Mattisson, Chem. Eng. Res. Des. 86 (2008) 1017-1026.

[23] A. Abad, J. Adanez, A. Cuadrat, F. Garcia-Labiano, P. Gayan, L.F. de Diego, Chem. Eng. Sci. 66 (2011) 689-702.

[24] I. Barin, Thermochemical Data of Pure Substances (1993).

[25] S. Noorman, M. Van Sint Annaland, H. Kuipers, Ind. Eng. Chem. Res. 46 (2007) 4212-4220.

[26] S. Noorman, F. Gallucci, M. Van Sint Annaland, J.A.M. Kuipers, Chem. Eng. J. 167 (2011) 297-307 
[27] J. Smit, M. van Sint Annaland, J.A.M. Kuipers, Chem. Eng. Sci. 60 (10) (2005) 2609-2619.

[28] B. Smith, R.J.M. Loganathan, M.S. Shantha, Int. J. Chem. Reactor Eng. 8 (2010) R4.
[29] G. Schwebel, H. Leion, W. Krumm, Chem. Eng. Res. Des. 90 (2012) 1351-1360.

[30] J.R. Fernandéz, J.C. Abanades, R. Murillo, G. Grasa, Int. J. Greenhouse Gas Control 6 (2012) 126-141.

[31] O. Levenspiel, D. Kunii, Fluidization Engineering (1991) (Chapter 3). 